\title{
Trading Population for Productivity: Theory and Evidence
}

\author{
Oded Galor and Andrew Mountford*
}

February 1, 2008

\begin{abstract}
This research argues that the differential effect of international trade on the demand for human capital across countries has been a major determinant of the distribution of income and population across the globe. In developed countries the gains from trade have been directed towards investment in education and growth in income per capita, whereas a significant portion of these gains in less developed economies have been channeled towards population growth. Cross-country regressions establish that indeed trade has positive effects on fertility and negative effects on education in non-OECD economies, while inducing fertility decline and human capital formation in OECD economies.
\end{abstract}

Keywords: International Trade, Demographic Transition, Growth, Human Capital

JEL Classification Numbers: O40, F11, F43, J10, N30

${ }^{*}$ The authors are grateful to the Editor, three referees, and Yona Rubinstein for their extensive valuable comments. In addition, they wish to thank Daron Acemoglu, Quamrul Ashraf, Anne Case, Francesco Caselli, Ronald Findlay, Gene Grossman, Elhanan Helpman, Wolfgang Keller, Joel Mokyr, Enrico Spolaore, David Weil, Jeff Williamson and seminar participants at Bern, Birmingham, Brown, Columbia, Harvard, Kent, Lille, Penn, Princeton, Royal Institute for International Affairs, Royal Holloway, University of London, Southampton, Tel-Aviv, and conference participants at the CEPR ERWIT, Munich, AEA Meetings, Minerva's Conference "From Stagnation to Growth", Economic Growth in the Very Long Run, Copenhagen, and NBER Summer Institute, for helpful comments. Galor: Brown University. Mountford: Royal Holloway, University of London. Galor's research is supported by NSF grant SES-0004304 and by the Rhodes Center for International Economics, Brown University. 


\section{Introduction}

The dramatic transformation in the distribution of income and population across the globe in the past two centuries is one of the most significant mysteries in the growth process. Some regions have excelled in the growth of income per capita while other regions have been dominant in population growth. ${ }^{1}$ This striking contrast between the development paths of large subsets of the world economy gives rise to fundamental questions about the growth process and its implications for current and historical development patterns. Notably, how does one account for the sudden take-off from stagnation to growth in some countries in the world and the persistent stagnation in others? Why have the differences in per capita incomes across countries increased so markedly in the last two centuries? Has the pace of transition to sustained economic growth in advanced economies adversely affected the process of development in less-developed economies? Have the forces of international trade contributed to the divergence in the timing of the demographic transition and the emergence of sustained economic growth across countries?

The origin of this 'Great Divergence' in income per capita has been a source of controversy. The relative roles of geographical and institutional factors, human capital formation, ethnic, linguistic and religious fractionalization, colonialism and globalization have been at the center of a debate about this remarkable change in the world income distribution in the past two centuries. ${ }^{2}$

This research suggests that international trade has played a significant role in the differential timing of demographic transitions across countries and has been a major determinant of the distribution of world population and the 'Great Divergence' in income per capita across countries in the last two centuries. The analysis suggests that international trade has an asymmetrical effect on the evolution of industrial and nonindustrial economies. While in the industrial nations the gains from trade have been directed primarily towards investment in education and growth in output per capita, a greater portion of the gains from trade in non-industrial nations has been channeled towards population growth.

The expansion of international trade enhanced the specialization of industrial economies in the production of industrial, skilled intensive, goods. The associated rise in the demand for skilled labor has induced a gradual investment in the quality of the population, expediting a demographic transition, stimulating technological progress and further enhancing the comparative advantage of these industrial economies in the production of skilled intensive goods. In non-industrial economies, in contrast, international trade has generated an incentive to specialize in the production of unskilled intensive, non-industrial, goods. The absence of significant demand for human capital has provided limited incentives to invest in the quality of

\footnotetext{
${ }^{1}$ In the time period 1820-1998, the ratio between income per capita in the richest region of the world and the poorest region of the world has increased from about 3 to 19. In particular, the ratio between income per capita in Western Europe and Asia grew nearly three-fold, whereas the ratio between the Asian population and the Western European population grew nearly two-fold (Maddison, 2001).

${ }^{2}$ North (1981), Landes (1998), Mokyr (2002), Hall and Jones (1999), Acemoglu, et al. (2005), Easterly and Levine (2003), Rodrik, et al. (2004) and Ashraf and Galor (2007) have argued that institutions that facilitated the protection of property rights and enhanced technological research, the diffusion of knowledge, and the transmission of society specific human capital, have been the prime factors that enabled the earlier European take-off and the great technological divergence across the globe. The effect of geographical factors on economic growth and the great divergence have been emphasized by Jones (1981), Diamond (1997), Gallup, Sachs and Mellinger (1998) and Pomeranz (2000). Finally, the role of human capital in the great divergence is underlined in unified growth theory (Galor, 2005; Galor and Weil 2000; Galor and Moav, 2002; McDermott, 2002; Doepke, 2004; Lagerlof, 2006; Galor et al., 2006) and is documented empirically by Glaeser et al. (2004).
} 
the population and the gains from trade have been utilized primarily for a further increase in the size of the population, rather than the income of the existing population. ${ }^{3}$ The demographic transition in these nonindustrial economies has been significantly delayed, increasing further their relative abundance of unskilled labor, enhancing their comparative disadvantage in the production of skilled intensive goods and delaying their process of development. The research suggests, therefore, that international trade has persistently affected the distribution of population, skills, and technologies in the world economy, and has been a significant force behind the 'Great Divergence' in income per capita across countries.

This paper develops a unified growth theory that captures the asymmetric role that international trade may have played in expediting the transition to sustained economic growth in technologically advanced economies and in delaying the transition in technologically inferior economies. The proposed theory is innovative in two dimensions. First, unlike the recent literature on the transition of economies from an epoch of Malthusian stagnation to a state of sustained economic growth that abstracted from the Great Divergence and focused on the evolution of the world economy from stagnation to growth, ${ }^{4}$ the proposed theory examines the differential patterns of takeoffs across regions in the world and the emergence of the Great Divergence. Second, in contrast to the existing literature on the dynamics of comparative advantage, ${ }^{5}$ the focus on the interaction between population growth and comparative advantage and the persistent effect that this interaction may have on the distribution of population and income in the world economy generates an important new insight regarding the distribution of the gains from trade. The theory suggests that even if trade equalizes output growth in the trading countries, (due to the terms of trade effect), income per capita of developed and less developed economies will diverge, since in developed economies the growth of total output will be generated primarily by an increase in output per capita, whereas in less developed economies the contribution of population growth to the growth of total output will be more significant. ${ }^{6}$

The theory is based on several fundamental elements. The interaction between these elements generates a dynamic pattern that is consistent with the observed asymmetrical evolution of the world economy from the epoch of Malthusian stagnation to the current era of sustained growth, characterized by widened differences in income per capita and population growth rates, as well as by persistent patterns of comparative advantage. Economies are initially in a Malthusian epoch in which the growth rate of output per capita is rather small and population growth is positively related to the level of income per capita. Technological progress leads ultimately to the adoption of more advanced agricultural and industrial technologies

\footnotetext{
${ }^{3}$ Evidence suggests that the returns to human capital may have been higher in LDCs. One can therefore mistakenly suppose that incentive to invest in child quality is higher in LDCs. However, these higher rates of return are not applicable to most individuals. They reflect a suboptimal investment in human capital in an environment characterized by credit market imperfections and limited access to schooling. International trade, therefore reduces further the modest demand for human capital and reduces further the incentive to substitute child quality for quantity.

${ }^{4}$ In particular, Galor and Weil $(1999,2000)$ argue that the inherent positive interaction between population and technology during the Malthusian regime increased the rate of technological progress sufficiently so as to induce investment in human capital which led to further technological progress, a demographic transition, and sustained economic growth.

${ }^{5}$ See Findlay and Kierzkowski (1983), Grossman and Helpman (1991), Stokey (1991), Young (1991), Matsuyama (1992), and Atkeson and Kehoe (2000), among others.

${ }^{6}$ See, for example, Acemoglu and Ventura (2002) for the terms of trade effect. Deardorff (1994) suggests that diverging (exogenous) population growth rates can lead to widening international inequality. Similarly, Krugman and Venables (1995) and Baldwin et al. (2001) argue that the reduction in transportation costs and the associated expansion in trade, generated geographically based industrialization and divergence.
} 
which paves the way for the take-off from the Malthusian epoch. International trade induces technologically advanced economies to specialize in the production of skilled intensive manufactured goods whereas technologically inferior economies specialize in the production of unskilled intensive agricultural goods. The increase in the demand for human capital in the technologically advanced economies that is brought about by international trade induces investment in human capital ${ }^{7}$ and expedites the demographic transition, ${ }^{8}$ whereas the reduction in the demand for human capital in less advanced economies delays the demographic transition and investment in human capital. ${ }^{9}$

The analysis demonstrates that the acceleration of the demographic transition in the technologically advanced economies increases their formation of human capital and brings about sustained technological progress that enhances their comparative advantage in the production of skilled intensive industrial goods. ${ }^{10}$ In contrast, the delay in the demographic transition in the less advanced economies increases the supply of unskilled workers and enhances the comparative advantage of these economies in the production of unskilled intensive goods. Thus, consistent with the evidence provided in sections 5 and 6 , the pattern of international trade has reinforced the initial patterns of comparative advantage and has generated a persistent effect on the distribution of population in the world economy and a great divergence in income per capita across countries and regions.

The fundamental hypothesis is tested empirically using contemporary cross country data. In accordance with the theory, cross country regressions support the hypothesis that international trade generates opposing effects on fertility rates and education in developed and less developed economies. The analysis establishes that a larger share of trade in GDP per capita has a positive effect on fertility and a negative effect on human capital formation in non-OECD economies, whereas in OECD economies, trade triggers a decline in fertility and an increase in human capital accumulation.

\section{An Autarkic Economy}

This section analyzes the path of a closed economy from its Malthusian pre-industrial state through a transitional state of increased fertility, investment in human capital and economic growth to a modern state with high investment in human capital, low population growth, and sustained economic growth. ${ }^{11}$

\footnotetext{
${ }^{7}$ Consistent with empirical evidence, the increased demand for human capital has not resulted necessarily in an increase in the equilibrium rate of return to human capital due to a massive supply response generated by (a) the increase in the incentive for investment in education (for a given cost), and (b) institutional changes (e.g., the provision of public education) that lowered the cost of investment in human capital.

${ }^{8}$ Unlike Becker (1981)'s hypothesis where a high level of income induces parents to switch to having fewer, higher quality children, the substitution of quality for quantity is in response to technological progress. The fact that demographic transitions occurred around the same period in Western European countries that differed in their income per capita, but shared a similar pattern of future technological progress, supports our technological approach.

${ }^{9}$ Moreover, the increased specialization of production within an economy would result, ceteris paribus, in increased income and fertility inequality within the economy, in line with the finding of Haines (2000) that fertility rate in rural areas remained higher than for urban areas for significant periods in the nineteenth century in both the US and UK, as well as with the findings of de la Croix and Doepke (2003) that income inequality causes differential fertility patterns within and across economies.

${ }^{10}$ Similarly to this element in the theory, Grossman and Helpman (1991) demonstrates that a country that begins with a head start in the accumulation of knowledge often leads in productivity over time.

${ }^{11}$ Galor and Mountford (2006) abstracts from these stages of development and demonstrates in a simpler Ricardian model that although international trade may equalize the growth rates of the value of total output in the two trading economies, since the rate of population growth in the technologically regressed economy is higher than that in the advanced economy, the rate of growth of output per capita in the technologically advanced economy will be higher than that in the technologically regressed
} 
Consider an overlapping-generations economy in which economic activity extends over infinite discrete time. In every period $t$, two goods, a manufactured good, $Y_{t}^{m}$, and an agricultural good $Y_{t}^{a}$, may be produced using up to three factors of production, skilled labor, $H_{t}$, unskilled labor, $L_{t}$, and land, $X$. The supply of skilled and unskilled labor is endogenously determined and evolves over time, whereas the quantity of land is exogenously determined and remains constant over time. ${ }^{12}$

\subsection{Production}

In each of the sectors of the economy production may take place with either an old technology or a new one. In early stages of development the new production technologies are latent and production is conducted using the old technologies. However, in the process of development the productivity of the new technologies grows faster than those of the old technologies and ultimately the new technologies become economically viable. In the agricultural sector, the introduction of the new technology represents the escape from the Malthusian trap, where wages do not fall despite an increase in population. In the industrial sector, the introduction of the new technology reflects an increase in the skill-intensity of the production process in the second phase of the industrial revolution and the associated increase in the demand for human capital.

\subsubsection{Production of the Agricultural Good}

The agricultural good can be produced by either an old technology or a new one. The output of the agricultural good produced with the old technology in period $t, Y_{t}^{a, 0}$, is

$$
Y_{t}^{a, 0}=a_{t}^{a}\left(L_{t}^{a, 0}\right)^{\gamma} X^{1-\gamma} ; \quad 0<\gamma<1,
$$

where $L_{t}^{a, 0}$ is the amount of unskilled labor and $X$ is the amount of land, employed in period $t$ in the production of the agricultural good using the old technology, and $a_{t}^{a}$ is the level of productivity of the old technology in period $t$. For simplicity the amount of land is normalized such that $X=1$.

The output of the agricultural good produced with the new technology in period $t, Y_{t}^{a, N}$, is governed by a constant returns to scale production technology ${ }^{13}$

$$
Y_{t}^{a, N}=A_{t}^{a} L_{t}^{a, N},
$$

where $L_{t}^{a, N}$ is the amount of unskilled labor employed in the production of the agricultural good in period $t$ using the new technology, and $A_{t}^{a}$ is the level of productivity of the new agricultural technology in period $t$.

As will become apparent, in the early stages of development when the productivity of the new agricultural technology, $A_{t}^{a}$, is low relative to the productivity of the old technology, $a_{t}^{a}$, only the old technology will be employed. However in later stages of development, when $A_{t}^{a}$ rises sufficiently relative to $a_{t}^{a}$, the new agricultural technology becomes economically viable.

\subsubsection{Production of the Manufactured Good}

The manufactured good can be produced by either an old technology or a new one. The output of the manufactured good produced with the old technology in period $t, Y_{t}^{m, 0}$, is

$$
Y_{t}^{m, 0}=a_{t}^{m} L_{t}^{m, 0}
$$

economy.

${ }^{12}$ Since the fundamental mechanism explored in this paper focuses on the role of human capital accumulation and the demographic transition in the process of development, the abstraction from the role of physical capital is a natural simplifying assumption.

${ }^{13}$ This production function is designed to capture the decline in the importance of land in mature state of development. However, as established in Appendix B, the qualitative analysis would remain intact if the agricultural technology remains land-intensive. 
where $L_{t}^{m, 0}$ is the amount of unskilled labor employed in period $t$ in the production of the manufactured good using the old technology, and $a_{t}^{m}$ is the level of productivity of the old industrial technology in period $t$.

The output of the manufactured good produced with the modern technology in period $t, Y_{t}^{m, N}$, is governed by a neoclassical constant returns to scale production function,

$$
Y_{t}^{m, N}=A_{t}^{m} F\left(H_{t}^{m}, L_{t}^{m, N}\right)=A_{t}^{m} f\left(h_{t}^{m}\right) L_{t}^{m, N},
$$

where $h_{t}^{m} \equiv H_{t}^{m} / L_{t}^{m, N}, A_{t}^{m}$ is the level of productivity of the new industrial technology in period $t$, and $L_{t}^{m, N}$ and $H_{t}^{m}$ are the amounts of unskilled labor and skilled labor employed in the production of the industrial good in period $t$ using the new technology.

As established below, in the early stages of development when the technological level $A_{t}^{m}$ is low relative to $a_{t}^{m}$ only the old industrial technology is economically viable. However in the process of development as $A_{t}^{m}$ rises sufficiently relative to $a_{t}^{m}$, it becomes profitable for producers to employ the new industrial technology.

\subsubsection{Factor Prices and Goods' Prices}

Producers operate in perfectly competitive markets for final goods and for labor. In the absence of property rights to land, the return to land is zero and workers in the agricultural sector who use the old technology receive their average products. ${ }^{14}$

The inverse demand for unskilled labor in the agricultural sector, given (1) and (2), is therefore

$$
w_{t}^{u}=\left\{\begin{array}{llc}
p_{t} a_{t}^{a}\left(L_{t}^{a, 0}\right)^{\gamma-1} & \text { if } & Y_{t}^{a, 0}>0 \\
p_{t} A_{t}^{a} & \text { if } & Y_{t}^{a, N}>0,
\end{array}\right.
$$

where $w_{t}^{u}$ is the wage of an unskilled labor in terms of the manufactured good, and $p_{t}$ as the relative price of the agricultural good in terms of the manufactured good in period $t$.

The inverse demand for skilled and unskilled labor in the manufactured sector, given (3) and (4), is therefore

$$
w_{t}^{u}=\left\{\begin{array}{lrl}
a_{t}^{m} & \text { if } \quad Y_{t}^{m, 0}>0 \\
A_{t}^{m}\left[f\left(h_{t}^{m}\right)-h_{t}^{m} f^{\prime}\left(h_{t}^{m}\right)\right] \equiv A_{t}^{m} w^{u}\left(h_{t}^{m}\right) & \text { if } \quad Y_{t}^{m, N}>0
\end{array}\right.
$$

and

$$
w_{t}^{s}=A_{t}^{m} f^{\prime}\left(h_{t}^{m}\right) \equiv A_{t}^{m} w^{s}\left(h_{t}^{m}\right) \quad \text { if } \quad Y_{t}^{m, N}>0 .
$$

Moreover,

$$
\frac{w_{t}^{s}}{w_{t}^{u}}=\frac{f^{\prime}\left(h_{t}^{m}\right)}{f\left(h_{t}^{m}\right)-h_{t}^{m} f^{\prime}\left(h_{t}^{m}\right)} \equiv \omega\left(h_{t}^{m}\right) \quad \text { if } \quad Y_{t}^{m, N}>0
$$

where as follows from the neoclassical properties of $f\left(h_{t}^{m}\right), \omega^{\prime}\left(h_{t}^{m}\right)<0, \lim _{h \rightarrow 0} \omega\left(h_{t}^{m}\right) \rightarrow \infty$, and $\lim _{h \rightarrow \infty} \omega\left(h_{t}^{m}\right)=$ 0 .

Since unskilled workers are mobile between the agricultural and the industrial sectors, the wages of unskilled labor in both sectors are equal if both goods are produced. As follows from (5) and (6), $p_{t}$, the

\footnotetext{
${ }^{14}$ See Galor and Weil (2000) for a discussion of alternative formulations in which property rights for land are present.
} 
relative price of the agricultural good in terms of the manufactured good in period $t$, is therefore

$$
p_{t}= \begin{cases}\frac{a_{t}^{m}}{a_{t}^{a}\left(L_{t}^{a, 0}\right)^{\gamma-1}} & \text { if } \quad Y_{t}^{a, 0}>0 \text { and } Y_{t}^{m, 0}>0 \\ \frac{a_{t}^{m}}{A_{t}^{a}} & \text { if } \quad Y_{t}^{a, N}>0 \text { and } Y_{t}^{m, 0}>0 \\ \frac{A_{t}^{m} w^{u}\left(h_{t}^{m}\right)}{a_{t}^{a}\left(L_{t}^{a, 0}\right)^{\gamma-1}} & \text { if } \quad Y_{t}^{a, 0}>0 \text { and } Y_{t}^{m, N}>0 \\ \frac{A_{t}^{m} w^{u}\left(h_{t}^{m}\right)}{A_{t}^{a}} & \text { if } \quad Y_{t}^{a, N}>0 \text { and } Y_{t}^{m, N}>0 .\end{cases}
$$

\subsection{Individuals: Fertility, Human Capital and Consumption}

Individuals live for two periods. In their first period of life they consume a fraction of their parental unit time endowment; educated offspring require a larger fraction of parental time. In their second period of life they are endowed with one unit of time of either skilled, $s$, or unskilled labor, $u$, which they optimally allocate between child rearing and labor force participation.

\subsubsection{Preferences and Budget Constraints}

Individual's preferences are defined over consumption and the potential aggregate income of their children. ${ }^{15}$ The preferences of a member $i, i=s, u$, of generation $t$ (i.e. an individual who is born in period $t-1$ ) are represented by the utility function

$$
u_{t}=\left(c_{t}^{i, a}\right)^{\alpha}\left(c_{t}^{i, m}\right)^{\beta}\left[w_{t+1}^{s} n_{t}^{i, s}+w_{t+1}^{u} n_{t}^{i, u}\right]^{1-\alpha-\beta},
$$

where $c_{t}^{i, a}$ and $c_{t}^{i, m}$ are individual $i$ 's consumption of the agricultural good and the consumption of the manufactured good, respectively. $\Sigma_{\{i=s, u\}} w_{t+1}^{i} n^{i}$ is the total potential income of individual $i$ 's offspring, where $n_{t}^{i, s}$ is the number of offspring trained to be skilled workers, $n_{t}^{i, u}$ is the number of offspring trained to be unskilled workers, and $w_{t+1}^{s}$ and $w_{t+1}^{u}$ are the wages paid to skilled and unskilled offspring in period $t+1 .{ }^{16}$ Individuals face subsistence consumption constraint and they must consume a subsistence level of the agricultural good, $\widetilde{c}$.

Individuals allocate their time between labor force participation and child rearing. They further choose both the number and quality of children and the amount of each good to consume. Denoting the time required to bring up a skilled offspring as, $\tau^{s}$, and the time required to bring up an unskilled offspring as, $\tau^{u}$, where $\tau^{s}>\tau^{u}$, the budget constraint of a member $i$ of generation $t, i=s, u$, is

$$
p_{t} c_{t}^{i, a}+c_{t}^{i, m}+w_{t}^{i}\left(n_{t}^{i, s} \tau^{s}+n_{t}^{i, u} \tau^{u}\right) \leq w_{t}^{i}
$$

\footnotetext{
${ }^{15}$ The number of children could be interpreted as the expected number of surviving children in a environment where due to infant mortality rate only a fraction of the children born will survive. As long as the cost of raising non-surviving children is insignificant the results will not be affected qualitatively. The results are identical if the cost of raising non-surviving children is zero and there is no uncertainty about the fraction of surviving children. Hence in an environment with higher infant mortality fertility rate will be mechanically higher.

${ }^{16}$ The subsistence consumption constraint generates the Malthusian positive income elasticity of population growth at low income levels. A Stone-Geary utility function of the form: $u_{t}=\left(c_{t}^{i, a}-\widetilde{c}\right)^{\alpha}\left(c_{t}^{i, m}\right)^{\beta}\left[w_{t+1}^{s} n_{t}^{i, s}+w_{t+1}^{u} n_{t}^{i, u}\right]^{1-\alpha-\beta}$ would generate identical qualitative results. The second component of the utility function may represent either intergenerational altruism, or implicit concern about potential support from children in old age. The interpretation that emphasizes intergenerational altruism reflects an implicit bounded rationality on the part of the parent. Alternative formulations according to which individuals generate utility from the utility of their children, or from the actual aggregate income of their offspring would require parental predictions about fertility choices of their dynasty. These approaches would greatly complicate the model but they would not affect the qualitative results.
} 


\subsubsection{Optimization}

A member $i$ of generation $t$ chooses $\left\{c_{t}^{i, a}, c_{t}^{i, m}, n_{t}^{i, s}, n_{t}^{i, u}\right\}$ so as to maximize the utility function:

$$
\left\{c_{t}^{i, a}, c_{t}^{i, m}, n_{t}^{i, s}, n_{t}^{i, u}\right\}=\arg \max \left(c_{t}^{i, a}\right)^{\alpha}\left(c_{t}^{i, m}\right)^{\beta}\left[w_{t+1}^{s} n_{t}^{i, s}+w_{t+1}^{u} n_{t}^{i, u}\right]^{1-\alpha-\beta}
$$

such that,

$$
\begin{aligned}
& p_{t} c_{t}^{i, a}+c_{t}^{i, m}+w_{t}^{i}\left(n_{t}^{i, s} \tau^{s}+n_{t}^{i, u} \tau^{u}\right) \leq w_{t}^{i} ; \\
& c_{t}^{i, a} \geq \widetilde{c} .
\end{aligned}
$$

The optimization depends on whether the subsistence consumption constraint is binding. If income is high enough, the constraint will not bind and the log-linearity of the utility function implies that fixed shares of potential income are devoted to child rearing and consuming each of the two goods. However if the subsistence consumption constraint binds then a greater share of potential income must be devoted to agricultural consumption.

The consumption of the agricultural good, $c_{t}^{i, a}$, by a member $i$ of generation $t$ is therefore

$$
c_{t}^{i, a}= \begin{cases}\widetilde{c} & \text { if } \quad \alpha \frac{w_{t}^{i}}{p_{t}}<\widetilde{c} \\ \alpha \frac{w_{t}^{i}}{p_{t}} & \text { if } \quad \alpha \frac{w_{t}^{i}}{p_{t}} \geq \widetilde{c} .\end{cases}
$$

The consumption of the manufactured good, $c_{t}^{i, m}$, by a member $i$ of generation $t$ is therefore

$$
c_{t}^{i, m}=\left\{\begin{array}{lll}
\frac{\beta}{1-\alpha}\left(w_{t}^{i}-p_{t} \widetilde{c}\right) & \text { if } \quad \alpha \frac{w_{t}^{i}}{p_{t}}<\widetilde{c} \\
\beta w_{t}^{i} & \text { if } \quad \alpha \frac{w_{t}^{i}}{p_{t}} \geq \widetilde{c} .
\end{array}\right.
$$

Furthermore, the number of educated and uneducated offspring will be determined such that the aggregate time devoted by a member $i$ of generation $t$ to child rearing is

$$
\left(n_{t}^{i, s} \tau^{s}+n_{t}^{i, u} \tau^{u}\right)=\left\{\begin{array}{lll}
\frac{1-\alpha-\beta}{1-\alpha} \frac{\left(w_{t}^{i}-p_{t} \widetilde{c}\right)}{w_{t}^{i}} & \text { if } \quad \alpha \frac{w_{t}^{i}}{p_{t}}<\widetilde{c} \\
(1-\alpha-\beta) & \text { if } \quad \alpha \frac{w_{t}^{i}}{p_{t}} \geq \widetilde{c},
\end{array}\right.
$$

where,

$$
\begin{array}{ccc}
n_{t}^{i, u}=0 & \text { if } & w_{t+1}^{s} / w_{t+1}^{u} \geq \tau^{s} / \tau^{u} \\
n_{t}^{i, s}>0 \text { and } n_{t}^{i, u}>0 & \text { only if } & w_{t+1}^{s} / w_{t+1}^{u}=\tau^{s} / \tau^{u} \\
n_{t}^{i, s}=0 & \text { if } & w_{t+1}^{s} / w_{t+1}^{u}<\tau^{s} / \tau^{u} .
\end{array}
$$

\subsection{Education and Fertility Decisions}

This section demonstrates that in the early stages of development, when the technological level is relatively low, individuals do not have an incentive to invest in the human capital of their offspring. However, as the level of technology improves in the process of development, the new industrial technology will ultimately become economically viable, human capital will be demanded and individuals will have an incentive to invest in the human capital of their offspring.

Lemma 1 Consider the new industrial sector. There exists a unique ratio of skilled to unskilled labor, $\left(h^{m}\right)^{*}$, such that

$$
\frac{w_{t}^{s}}{w_{t}^{u}}=\omega\left(\left(h^{m}\right)^{*}\right)=\frac{\tau^{s}}{\tau^{u}}
$$


where,

$$
\begin{array}{lll}
n_{t}^{i, u}=0 & \text { if } & h_{t}^{m}<\left(h^{m}\right)^{*} \\
n_{t}^{i, s}=0 & \text { if } & h_{t}^{m}>\left(h^{m}\right)^{*} .
\end{array}
$$

Proof. The uniqueness of $\left(h^{m}\right)^{*}$ follows from the properties of $\omega\left(h_{t}^{m}\right)$, noting that $\tau^{s} / \tau^{u}>0$. The remaining part is a corollary of $(14)$.

Hence, if $h_{t+1}^{m}<\left(h^{m}\right)^{*}$ then individuals would not have an incentive to raise unskilled offspring and the skilled to unskilled ratio will increase, whereas if $h_{t+1}^{m}>\left(h^{m}\right)^{*}$ then individuals would not have an incentive to raise skilled offspring and the skilled to unskilled ratio will decline until $h_{t+1}^{m}=\left(h^{m}\right)^{*}$.

Corollary 1 If the new industrial technology is employed then $h_{t}^{m}=\left(h^{m}\right)^{*}$, i.e.,

$$
h_{t}^{m}=\left(h^{m}\right)^{*} \quad \text { if } \quad Y_{t}^{m, N}>0,
$$

and therefore

$$
\begin{array}{ccc}
w_{t}^{u}=A_{t}^{m} w^{u}\left(\left(h^{m}\right)^{*}\right) & \text { if } & Y_{t}^{m, N}>0 ; \\
p_{t}=\frac{A_{t}^{m} w^{u}\left(\left(^{m}\right)^{*}\right)}{A_{t}^{a}} & \text { if } & Y_{t}^{a, N}>0 \text { and } Y_{t}^{m, N}>0 .
\end{array}
$$

\subsection{Aggregate Labor Allocation}

Since preferences are such that both goods are consumed in every period, in autarky both goods must be produced in every period. Hence an equilibrium in the goods market requires that, in a given technological state, the demand for the agricultural and the industrial goods given by (11) and (12) equal the supply of the two goods given by (1)-(4).

Lemma 2 If both goods are produced only with the old technology

(a) The employment of labor in the agricultural sector is

$$
L_{t}^{a, 0}=\left\{\begin{array}{lll}
{\left[\frac{\widetilde{c}}{a_{t}^{a}} N_{t}\right]^{1 / \gamma}} & \text { if } & \alpha \frac{w_{t}^{u}}{p_{t}}<\widetilde{c} \\
\alpha N_{t} & \text { if } & \alpha \frac{w_{t}^{u}}{p_{t}} \geq \widetilde{c} .
\end{array}\right.
$$

(b) The employment of labor in the industrial sector is

$$
L_{t}^{m, 0}=\left\{\begin{array}{lll}
\frac{\beta}{1-\alpha}\left(N_{t}-\left[\frac{\widetilde{c}}{a_{t}^{a}} N_{t}\right]^{1 / \gamma}\right) & \text { if } & \alpha \frac{w_{t}^{u}}{p_{t}}<\widetilde{c} \\
\beta N_{t} & \text { if } & \alpha \frac{w_{t}^{u}}{p_{t}} \geq \widetilde{c} .
\end{array}\right.
$$

(c) The aggregate time devoted to child rearing is

$$
\Sigma_{\{i=s, u\}} n_{t}^{i, u} \tau^{u}=\left\{\begin{array}{lll}
\frac{(1-\alpha-\beta)}{(1-\alpha)}\left(N_{t}-\left[\frac{\widetilde{c}}{a_{t}^{a}} N_{t}\right]^{1 / \gamma}\right) & \text { if } & \alpha \frac{w_{t}^{u}}{p_{t}}<\widetilde{c} \\
(1-\alpha-\beta) N_{t} & \text { if } & \alpha \frac{w_{t}^{u}}{p_{t}} \geq \widetilde{c} .
\end{array}\right.
$$

Proof. Follows from (1), (3),(11)-(13), noting that $w_{t}^{u} / p_{t}=a_{t}^{a}\left(L_{t}^{a, 0}\right)^{\gamma-1}$. 


\subsection{Viability of the New Technologies}

The new industrial technology will become economically viable if the value of the marginal product of unskilled workers who use this new technology, $A_{t}^{m} w^{u}\left(\left(h^{m}\right)^{*}\right)$, is at least as high as that of unskilled workers who use the old industrial technology, $a_{t}^{m}$.

The new agricultural technology will become economically viable if the value of the marginal product of unskilled workers who use this new technology, $p_{t} A_{t}^{a}$, is at least as high as the return to unskilled workers who use the old industrial technology, $p_{t} a_{t}^{a}\left(L_{t}^{a, 0}\right)^{\gamma-1}$.

Lemma 3 (a) The new industrial technology is economically viable if $f^{17}$

$$
\frac{A_{t}^{m}}{a_{t}^{m}} \geq 1 /\left[w^{u}\left(\left(h^{m}\right)^{*}\right)\right] .
$$

(b) The new agricultural technology is economically viable if

$$
\frac{A_{t}^{a}}{a_{t}^{a}} \geq\left(L_{t}^{a, 0}\right)^{\gamma-1} .
$$

where $L_{t}^{a, 0}$ is given by Lemma 2.

Proof. (a) $Y_{t}^{m, N}>0$ if the marginal productivity of unskilled labor in the new industrial sector is at least as high as in the old industrial sector. Hence part (a) follows from (6) and Corollary 1.

(b) $Y_{t}^{a, N}>0$ if the marginal productivity of unskilled labor in the new agricultural sector is at least as high as in the old agricultural sector. Hence part (b) follows from (5).

\section{The Time Path of Macroeconomic Variables}

\subsection{Technological Progress}

Suppose that technological progress, $g_{t+1}$, that takes place between periods $t$ and $t+1$ is affected positively by the skill intensity of the workforce in period $t, h_{t}$.

$$
g_{t+1} \equiv \frac{\lambda_{t+1}-\lambda_{t}}{\lambda_{t}}=g\left(h_{t}\right)
$$

where $g\left(h_{t}\right)$ is an increasing concave function $\left(g^{\prime}\left(h_{t}\right)>0\right.$ and $\left.g^{\prime \prime}\left(h_{t}\right)<0\right)$. Furthermore, the rate of technological progress is positive even if the labor force consists of only unskilled labor (i.e., $g(0)>0){ }^{18}$

Suppose that the productivity levels in each sector are functions of the level of a General Purpose Technology in the economy as a whole. Namely, the productivity of the old and the new technologies in the agricultural sector, $a$, and the industrial sector, $m$, are

$$
\begin{aligned}
& A_{t}^{j}=A^{j}\left(\lambda_{t}\right) \\
& a_{t}^{j}=a^{j}\left(\lambda_{t}\right)
\end{aligned}
$$

where, $d A^{j} / d \lambda>0$ and $d a^{j} / d \lambda>0, j=a, m$.

\footnotetext{
${ }^{17}$ When $A^{m} w^{u}\left(h_{m}^{*}\right)=a^{m}$ then there is indeterminacy in the choice of how many skilled and unskilled offspring to produce. This indeterminacy can be resolved by assuming that ceteris paribus parents prefer educated children. The indeterminacy resolves itself after one period in any case as technology progresses.

${ }^{18}$ The qualitative analysis would not be altered if the growth rate of technology would affect the return to human capital. As is established in Appendix B, if the agricultural technology remains land-intensive then it is the rate of growth of technology that is vital. Although the threshold and the rate of growth models are theoretically distinct mechanisms, they are both consistent with the same set of facts i.e. a growing rate of technological change occurring alongside an increase in the rate of human capital accumulation and a non-monotonic relationship between population growth and income.
} 
The productivity parameters are restricted so as to assure that the process of technological progress is consistent with its historical patterns:

(a) The new industrial and agricultural technologies are not economically viable in period 0, i.e.,

$$
\begin{gathered}
\frac{A_{0}^{m}}{a_{0}^{m}}<1 /\left[w^{u}\left(\left(h^{m}\right)^{*}\right)\right] ; \\
\frac{A_{0}^{a}}{a_{0}^{a}}<\left(L_{0}^{a, 0}\right)^{\gamma-1}=\left(\frac{\widetilde{c} N_{0}}{a_{0}^{a}}\right)^{\frac{\gamma-1}{\gamma}}
\end{gathered}
$$

where $N_{0}>0$ is the initial size of the adult population.

(b) The advancement in the productivity of the industrial sector is larger than that in the agricultural sector, ${ }^{19}$ and the new technologies advance more rapidly than the old ones, i.e., ${ }^{20}$

$$
\frac{d A^{m}\left(\lambda_{t}\right)}{d \lambda_{t}}>\frac{d A^{a}\left(\lambda_{t}\right)}{d \lambda_{t}}>\frac{d a^{m}\left(\lambda_{t}\right)}{d \lambda_{t}}>\frac{d a^{a}\left(\lambda_{t}\right)}{d \lambda_{t}}>0 ; \quad \lim _{\lambda_{t} \rightarrow \infty} \frac{A^{j}\left(\lambda_{t}\right)}{a^{j}\left(\lambda_{t}\right)}=\infty \quad j=a, m .
$$

Condition A2 ensures that a more technologically advanced economy has a comparative advantage in the industrial good. ${ }^{21}$

Lemma 4 Under A1, A2

(a) there exists a time period $\left(t^{m}\right)^{*}$ in which the new industrial technology becomes economically viable, i.e.,

$$
\frac{A_{t}^{m}}{a_{t}^{m}} \geq 1 /\left[w^{u}\left(\left(h^{m}\right)^{*}\right)\right] \quad \forall t \geq\left(t^{m}\right)^{*},
$$

(b) there exists a time period $\left(t^{a}\right)^{*}$ in which the new agricultural technology becomes economically viable, i.e.,

$$
\frac{A_{t}^{a}}{a_{t}^{a}} \geq\left(\left(L_{t}^{a, 0}\right)^{*}\right)^{\gamma-1} \quad \forall t \geq\left(t^{a}\right)^{*},
$$

where $\left(L_{t}^{a, 0}\right)^{*}$ is the level of employment in the old agricultural sector necessary for the old agricultural sector alone to satisfy the total demand for agricultural products at time $t$.

Proof. See Appendix.

In order to simplify the determination of factor prices, the new agricultural technology is assumed to become economically viable before the new industrial technology, i.e.,

$$
\left(t^{a}\right)^{*}<\left(t^{m}\right)^{*}
$$

This assumption assures that the static structure of the model resembles the Ricardo-Viner trade model. In any period wages of skilled and unskilled workers are determined by either the constant marginal productivity of unskilled labor in the old industrial sector (prior to the employment of the modern agricultural

\footnotetext{
${ }^{19}$ These assumptions are consistent with historical evidence that suggests that productivity in the agricultural sector grew less rapidly than in the industrial sector over the late part of the 18th century and the entire 19th century. In particular, sectoral productivity growth in the UK in the period 1780-1860 was estimated by McCloskey (1981) to be $1.8 \%$ in the modernized sector and $0.45 \%$ in the agricultural sector. The gap was revised downward by Harley (1999) who estimate productivity growth in the modernized sector to be $1.2 \%$ and $0.7 \%$ in the agricultural sector.

${ }^{20}$ Despite the fact that modern production technology is not employed over a certain period of time, the advancement in knowledge permits the advancement in the productivity of this potential technology to be faster than the older one. For instance, early vintages of the steam engines were very inefficient and thus were not used. However, advancement in knowledge permitted this technology to advance rather rapidly and to become effective. Namely, the advancement in the latent technology is via learning by doing in the laboratory rather than in the industry.

${ }^{21} \mathrm{As}$ follows from (9), condition A2 also has the implication that the relative price of the agricultural good is monotonically increasing over time. Evidence suggests that the relative price of agricultural goods rose over the period 1880-1920 and declined over the period 1920-1990 (Caselli and Coleman, 1999). This pattern can be easily matched if the cost of acquiring skills would vary over time. In particular, if the cost of acquiring skills is increasing over time, (i.e. $\tau^{s} / \tau^{u}$ is increasing with $\lambda$.), the relative price of agricultural goods could decrease over time.
} 
technology), or the constant marginal productivity of unskilled workers in the agricultural sector (once the modern agricultural technology is used). As established in the Appendix, the qualitative result would not be affected if this structure is not imposed.

\subsection{Human Capital Accumulation}

The evolution of human capital accumulation is characterized by three regimes. In the time period $t<\left(t^{m}\right)^{*}$, as long as the new industrial technology is not economically viable, there is no demand for skilled individuals and thus parents will not raise skilled children and the proportion of skilled labor in the labor force will be zero. In the time interval $\left(t^{m}\right)^{*} \leq t \leq \tilde{t}$, once the new industrial technology is economically viable, but the subsistence consumption constraint is still binding for at least unskilled parents, skilled children will be raised, and while the proportion of skilled labor in the industrial sector will be constant at a level, $\left(h^{m}\right)^{*}$, the proportion of skilled labor in the entire labor force, $h_{t+1}$, will depend upon the demand for human capital as reflected by the level of technology, $\lambda_{t+1}$. Technological progress and its effect of household income will gradually relax the bindingness of the subsistence agricultural consumption constraint, and will increase the budget share that is devoted to the consumption of the industrial goods. It will therefore generate an increase in the fraction of the labor force employed in the production of industrial goods, increasing the proportion of skilled labor in the entire labor force. Finally, in the time interval $t \geq \tilde{t}$, once the subsistence consumption constraint is no longer binding, technological advancements would not affect the budget share devoted to any of the goods, and the proportion of skilled individuals in the entire labor force will be a constant at a level $\tilde{h}$.

Lemma 5 The proportion of skilled labor in the entire labor force at time $t+1, h_{t+1}$, is

$$
h_{t+1}=\left\{\begin{array}{lll}
0 & \text { if } \quad Y_{t+1}^{m, N}=0 \\
h\left(\lambda_{t+1}\right) & & Y_{t+1}^{a, 1}>0 ; Y_{t+1}^{m, N}>0 ; c_{t}^{a, u}<\tilde{c} \\
\tilde{h} & \text { if } \quad Y_{t+1}^{a, N}>0 ; Y_{t+1}^{m, N}>0 ; c_{t}^{a, u}>\tilde{c},
\end{array}\right.
$$

where $h^{\prime}\left(\lambda_{t+1}\right)>0$.

Proof. See Appendix.

Hence, as follows from Lemma 4, Lemma 5, and (15), the evolution of the proportion of skilled labor in the entire labor force is

$$
h_{t+1}= \begin{cases}0 & \text { if } t<\left(t^{m}\right)^{*} \\ h\left(\left[1+g\left(h_{t}\right)\right] \lambda_{t}\right) & \text { if } \quad\left(t^{m}\right)^{*} \leq t \leq \tilde{t} \\ \tilde{h} & \text { if } t \geq \tilde{t},\end{cases}
$$

where $\tilde{t}$ is the time period in which the subsistence consumption constraint is no longer binding even for unskilled parents

\subsection{Population Dynamics}

The evolution of population is characterized by four regimes. In the time period $t<\left(t^{a}\right)^{*}$, the economy is in Malthusian regime where population growth is determined by the rate of technological progress. Technological progress temporarily raises real wages, but in the absence of further technological advancements, these gains are gradually eroded by population growth. Due to diminishing returns to labor in the agricultural sector, population growth reduces real wages and future fertility until population growth falls to zero. In the time period $\left(t^{a}\right)^{*}<t<\left(t^{m}\right)^{*}$, the emergence of the new agricultural technology permits an advancement of population without a reduction in real wages. Thus income per capita increases along with population 
growth. In the time period $\left(t^{m}\right)^{*}<t<\tilde{t}$, the new technology in the industrial sector becomes viable but the subsistence consumption constraint is still binding for at least unskilled parents. The rise in the demand for human capital provides an incentive for parents to raise skilled children. Hence, a decline in the rate of population growth eventually accompanies the rise in income per capita. Finally, in the time interval $t \geq \tilde{t}$, once the subsistence consumption constraint is no longer binding, technological advancements do not affect the budget share devoted to industrial production. The proportion of skilled individuals in the entire labor force with constant at a level $\tilde{h}$, and the rate of population growth is constant as well.

Lemma 6 The evolution of population is characterized by four regimes .

$$
N_{t+1}= \begin{cases}\phi^{1}\left(\lambda_{t}, N_{t}\right) & \text { if } Y_{t+1}^{a, N}=0 ; \\ \phi^{2}\left(\lambda_{t}, N_{t}\right) & \text { if } Y_{t+1}^{a, N}>0 ; Y_{t+1}^{m, O}>0 ; \\ \phi^{3}\left(\left[1+g\left(h_{t}\right)\right] \lambda_{t}, \lambda_{t}, N_{t}\right) & \text { if } Y_{t+1}^{a, N}>0 ; Y_{t+,}^{m, N}>0 ; c_{t}^{a, u}<\tilde{c} \\ \widetilde{n} N_{t} & \text { if } Y_{t+1}^{a, N}>0 ; Y_{t+1}^{m, N}>0 ; c_{t}^{a, u}>\tilde{c} .\end{cases}
$$

where $\partial \phi^{j} / \partial N_{t}>0$ for all $j=1,2,3, \partial \phi^{j} / \partial \lambda_{t}>0$ for $j=1,2$, and $\widetilde{n} \equiv(1-\alpha-\beta)\left[(1+(\tilde{h} /(1-\tilde{h}))] /\left[\left(\tau^{u}+\right.\right.\right.$ $\left.(\tilde{h} /(1-\tilde{h})) \tau^{s}\right]$.

Proof. Follows from (13),(14), Lemma 5, and Lemma A1, noting that $\tau_{s}>\tau_{u}$.

\subsection{Industrialization and Demographic Transition}

In advanced stages of development (i.e., $t>\left(t^{m}\right)^{*}>\left(t^{a}\right)^{*}$ ), the new industrial technology is economically viable and there is a demand for skilled labor. This stage of development is characterized by self-reinforcing interaction between technological progress and the human capital intensity in the labor force. As established in Lemma 5, the level of technology has a positive effect on the proportion of skilled labor in the entire labor force, while the skill-intensity of the labor force governs the pace of technological advancement.

As established in the lemma below, technological progress generates two conflicting forces on the rate of population growth. On the one hand, it raises the wage level and thus household's income, increasing the budget share devoted to manufactured goods, and therefore the demand for skilled workers. Hence, since $\tau^{s}>\tau^{u}$, technological progress provides an inducement for lower fertility rates.. However, on the other hand, the rise in household's income allows more resources to be devoted to raising children, exerting a positive influence on the level of fertility.

Lemma 7 If the new technologies are economically viable in both sectors, and if the subsistence constraint is binding for skilled and unskilled workers, then the total number of offspring $n_{t}^{i}$, of an individual $i, i=s, u$, is

$$
n_{t}^{i}=\frac{(1-\alpha-\beta)\left(1-p_{t} \tilde{c} / w_{t}^{i}\right)\left[1+\left(l^{u}\left(\lambda_{t+1}\right) / l^{s}\left(\lambda_{t+1}\right)\right)\left(h\left(\lambda_{t+1}\right) /\left(1-h\left(\lambda_{t+1}\right)\right)\right)\right]}{\left[(1-\alpha)\left(\tau^{u}+\left(l^{u}\left(\lambda_{t+1}\right) / l^{s}\left(\lambda_{t+1}\right)\right)\right)\left(h\left(\lambda_{t+1}\right) /\left(1-h\left(\lambda_{t+1}\right)\right) \tau^{s}\right)\right]} \equiv n^{i}\left(w_{t}^{i} / p_{t}, \lambda_{t+1}\right) .
$$

Proof. Follows from the definition of $h_{t+1}$ in the proof of Lemma 5, noting (13).

The theory generates the inverted ' $U$ ' shaped pattern that characterizes the evolution of population growth in the course of economic development. ${ }^{22}$ As established in (13), the rise in income in early stages of development in which the subsistence consumption constraint is binding, increases the share of parental time that is devoted to child rearing. However, since investment in education is not rewarded in this stages of development, the entire increase in the share of parental time that is devoted to child rearing is allocated towards an increase in the number of uneducated children. Hence, the rise in income per-capita in the take-off

\footnotetext{
${ }^{22}$ Fertility will necessarily decline in the transition to the modern regime if $\beta, \tau^{s}$, and $\omega^{-1}\left(\tau^{s} / \tau^{u}\right)$, are sufficiently high.
} 
from the Malthusian epoch results in a gradual increase in population growth. The inevitable introduction of the modern industrial technology brings about a demand for educated labor and the increasing parental resources that are allocated to child rearing are devoted partially towards educated children. The gradual increase in the reward to education shifts the allocation of resources toward child quality and population growth ultimately declines.

\subsection{The Modern Industrial Stage}

In the modern industrial stage, the level of technology generates a sufficiently high income level for each household such that the subsistence constraint is no longer binding. The economy reaches a state where the population growth rate and the skill intensity of the economy are constant. The budget share devoted to manufactured goods and the level of human capital accumulation is higher than in the previous stage of development and the fertility rate is lower. The growth of income per capita is therefore higher, noting that the rate of technological progress, $g_{t+1}=g\left(h_{t}\right)$, increases in the skill intensity of the labor force.

Proposition 1 If the new technologies are economically viable in both sectors and neither skilled nor unskilled workers are constrained by the subsistence constraint, the economy is in a state of balanced growth with a constant population growth rate, $\tilde{n}=\left[(1-\alpha-\beta)(1+(\widetilde{h} /(1-\widetilde{h}))] /\left[\tau^{u}+(\widetilde{h} /(1-\widetilde{h})) \tau^{s}\right]\right.$, and constant skill intensity, $\widetilde{h}$.

Proof. Follows from (13), Lemma 5, and Lemma 7.

Corollary 2 If the new technologies are economically viable in both sectors and neither skilled nor unskilled workers are constrained by the subsistence constraint, the budget share devoted to manufactured goods and the level of human capital accumulation will be higher than in the previous stages and the fertility rate will be lower than the level in the previous stage.

Proof. Follows from (13), Lemmas A1, 5, and 7,.

\section{International Trade and the Process of Development}

This section analyzes the effect of international trade on economies' transition to a state of sustained economic growth. The analysis demonstrates that international trade accelerates the transition of technologically advanced economies to a state of sustained growth, whereas it prolongs the transition of less advanced economies to a state of sustained economic growth, perhaps indefinitely.

\subsection{Comparative Advantage}

Suppose that the world economy consists of two economies that are identical in every respect except for their level of technology. In particular, economy $A$ is more technologically advanced than economy $B$ and therefore possesses more advanced technologies for the production of the industrial good as well as for the agricultural good, i.e.,

$$
\begin{aligned}
& {\left[A_{t}^{m}\right]^{A}>\left[A_{t}^{m}\right]^{B} ;} \\
& {\left[A_{t}^{a}\right]^{A}>\left[A_{t}^{a}\right]^{B} .}
\end{aligned}
$$

Furthermore, since technological progress in the industrial sector is faster than in the agricultural sector, the industrial technology is relatively more advanced in economy A, and the technologically advanced country has a comparative advantage in the production of the industrial good, i.e., 


$$
\left\{\frac{A_{t}^{m}}{A_{t}^{a}}\right\}^{A}>\left\{\frac{A_{t}^{m}}{A_{t}^{a}}\right\}^{B}
$$

\subsection{Autarkic and Trade Equilibrium}

Suppose that international trade does not take place prior to the stage in which the new production technologies become economically viable. As established above, since technological advancement is biased towards the industrial sector, the autarkic relative price of the agricultural good, $p^{A}$, in the technologically advanced economy, $A$, is higher than the autarkic relative price, $p^{B}$, in the less technologically advanced economy, $B$. That is, as follows from (9) and Corollary 1, once the two advanced technologies are economically viable in both economies, i.e., $\left[Y_{t}^{a, N}\right]^{i}>0$ and $\left[Y_{t}^{m, N}\right]^{i}>0$, for $i=a, b$,

$$
\begin{aligned}
& p_{t}^{A}=\frac{\left[A_{t}^{m}\right]^{A} w^{u}\left(\left(h^{m}\right)^{*}\right)}{\left[A_{t}^{a}\right]^{A}} ; \\
& p_{t}^{B}=\frac{\left[A_{t}^{m}\right]^{B} w^{u}\left(\left(h^{m}\right)^{*}\right)}{\left[A_{t}^{a}\right]^{B}},
\end{aligned}
$$

where as follows from (19),

$$
p_{t}^{A}>p_{t}^{B}
$$

As international trade is established between the two countries, the international equilibrium relative price of the agricultural good, $p_{t}^{*}$, is determined in between the autarkic equilibrium prices, $p_{t}^{A}$ and $p_{t}^{B}$ of the two economies,

$$
p_{t}^{B} \leq p_{t}^{*} \leq p_{t}^{A} .
$$

\subsection{Patterns of Specialization}

International trade therefore causes each of the countries to specialize relative to their position in autarky. Furthermore, it follows from (19) and (20) that one of the economies completely specializes in production. (If $p_{t}^{B}<p_{t}^{*}<p_{t}^{A}$, the two economies completely specialize in production). ${ }^{23}$ From the viewpoint of the technologically advanced economy, $A$, there is reduction in the relative price of the agricultural good, and producers are induced to produce more of the industrial good. From the viewpoint of the less advanced economy, $B$, there is an increase in the relative price of the agricultural good and producers are induced to produce more of the agricultural good. International trade, therefore induces economy $A$ to specialize in the production of the industrial, skilled intensive, good, whereas economy $B$ is induced to specialize in the production of the agricultural good.

\subsection{Trade and Population Growth}

The effect of international trade on the patterns of specialization in production in period $t$, affects the demand for skilled and unskilled labor in the two economies in period $t$, and generates an advanced supply response from parents who are taking decisions about the optimal number of skilled and unskilled children to raise in period $t-1$ in light of the expected rate of return for skilled and unskilled workers in period $t$.

Proposition 2 If the world economy is opened to international trade:

(a) The rate of population growth of the technologically advanced economy, A, is affected negatively

(b) The rate of population growth of the technologically less advanced economy, B is affected positively.

${ }^{23}$ The patterns of comparative advantage determined by this semi-Ricardian structure is consistent with recent evidence provided by Estavadoerdal and Taylor (2002) which shows that the Heckesher-Ohlin structure does not fit well the patterns of trade in 1913. 


\section{Proof.}

(a) Since $p_{t}^{B} \leq p_{t}^{*} \leq p_{t}^{A}$, international trade increases necessarily the production of the skilled intensive industrial good in economy A (even if the economy remains diversified). The ratio of skilled workers in the economy $\left[h_{t}\right]^{A}$ increases and since the production of skilled children requires more time, the rate of population growth declines. In particular, if $p_{t}^{*}<p_{t}^{A}$ then economy $A$ completely specializes in the production of the industrial good, $\left[h_{t}^{m}\right]^{A}=\left(h^{m}\right)^{*}$ and population growth decreases.

(b) Since $p_{t}^{B} \leq p_{t}^{*} \leq p_{t}^{A}$, international trade increases necessarily the production of the unskilled intensive agricultural good in economy $B$ (even if the economy remains diversified). The ratio of skilled workers in the economy $\left[h_{t}\right]^{B}$ declines and since the production of unskilled children requires less time, the rate of population growth rises. In particular, if $p_{t}^{B}<p_{t}^{*}$ then economy $B$ completely specializes in the production of the agricultural good, $\left[h_{t}^{m}\right]^{B}=0$ and population growth increases.

Population growth in the two economies prior to the demographic transition is affected positively by the aggregate resources of the economy and negatively by the rate of return to human capital. The effect of international trade expedites the demographic transition in the technological advanced economy, $A$, whereas it slows it down in the technologically less advanced economy, $B$.

Proposition 3 If the world economy is opened to International trade

(a) The demographic transition of the technologically advanced economy, A, is accelerated

(b) The demographic transition of the technologically less advanced economy, B, is delayed, perhaps indefinitely,

Proof. As established below in Proposition 4, international trade widens the technological gap between the advanced and the less advanced economies. The relative income of economy $B$ in the world economy depends on its rate population growth relative to that of the advanced economy $A$. If the share of income of economy $\mathrm{B}$ in the world economy falls over time then economy $B$ could completely specialize in agricultural production, and the economy would never generate a demand for skilled workers and would therefore not experience a demographic transition. Alternatively if the relative share of income of economy $B$ in the world economy rises over time then ultimately the output of the manufactured good in economy $A$ will be insufficient to meet world demand, and economy $B$ would begin demanding skilled workers and eventually would experience a demographic transition. For economy $A$ international trade increases the rate of technological progress and thereby the demand for skilled labor, accelerating the demographic transition.

\subsection{Trade and the Technological Gap}

This initial effect of international trade on population growth will persist, and the initially less advanced economy will become even relatively less advanced through time.

Proposition 4 International trade widens the technological gap between the advanced and less advanced economies.

Proof. As follows from (15), the increase in the proportion of skilled workers $\left[h_{t}\right]^{A}$ in the technologically advanced economy increases the rate of technological progress in the economy, whereas the reduction in the proportion of skilled workers $\left[h_{t}\right]^{B}$ in the technologically less advanced economy, decreases its rate of technological progress. Since $g^{\prime}\left(h_{t}\right)>0$ the proposition follows.

Corollary 3 International trade reinforces the initial patterns of comparative advantage. 


\subsection{The Effect of Trade in a Multi-Country Setting}

The model presented here is highly stylized. However the economic mechanisms derived in the paper would still hold in more detailed models. In a model with more than two economies, for example, the effect of trade on fertility and human capital in intermediate economies will depend on its overall trading position. If trade increases an intermediate economy's demand for human capital, via its comparative advantage in human capital intensive goods with less developed economies, then trade will accelerate the intermediate economy's transition to the modern industrial stage for the reasons derived in Proposition 3. Thus the model is consistent with the rapid growth of intermediate economies, such as the Asian Tigers, even without the presence of complementary industrial policies.

\section{Cross Country Evidence}

This section uses cross country regressions to examine empirically the hypothesis that the effect of international trade on the demand for human capital induces a rise in fertility and a decline in human capital formation in non-industrial economies, and a decline in fertility and a rise in human capital formation in industrialized economies.

The empirical analysis focuses on a recent time period in which most countries have already experienced their demographic transition. In particular, we examine the effect of the share of trade in GDP in 1985 on Total Fertility Rate (TFR) and on the change in the average years of schooling in industrial and non-industrial economies over the time period 1985-1990. ${ }^{24}$ The choice of this time period reflects the desirability of the use of the Frankel and Romer (1999) instrument for a country's intrinsic propensity to trade in 1985, so as to overcome the potential existence of omitted variables, measurement errors, and reverse causality from fertility and human capital formation to trade patterns. In the absence of authoritative data on the factor content of trade that would have enabled us to divide the world into economies which export human capital intensive goods and those which export unskilled labor intensive goods, we test our hypothesis on a pre-existing division of the world economy, and consider OECD economies in 1985 as those who export on average human capital intensive goods and non-OECD economies in 1985 as those who export unskilled intensive goods. ${ }^{25}$ The sample consists of 132 countries for the fertility regressions and 97 countries for the human capital accumulation regressions. ${ }^{26}$

The theory suggests that international trade, via its effect on the patterns of specialization, would increase the demand for human capital in the OECD economies and decrease the demand for human capital in non-OECD economics. This would generate a force towards a decline in fertility rates and an increase in human capital investment in OECD economies and towards a rise in fertility rates and a decline in human capital investment in non-OECD economies. The gains from international trade, however, would be expected to generate a rise in income in both OECD and non-OECD countries. In the pre-demographic transition

\footnotetext{
${ }^{24}$ See the Appendix for the definitions and summary statistics of all variables.

${ }^{25}$ Trefler and Zhu (2005) provide supporting evidence for this segmentation and the underlying difficulties in estimating the factor content of trade.

${ }^{26}$ OPEC economies are omitted from the sample since their trade patterns do not capture the characteristics underlined by the theory and the wealth effect associated with their oil revenues could potentially distort the relationship between trade, fertility and education. In addition, Reunion is excluded from the sample since it is an integral part of the French Republic and is thus not an independent observation. The incorporation of OPEC economies and Reunion into the analysis, or the inclusion of a dummy variable for OPEC economies does not alter the qualitative results.
} 
era these gains in income would be channeled towards an increase in fertility rates. They would therefore enhance the increase in fertility rates in less developed economies and would offset some of the negative effect of the rise in the demand for human capital on fertility in developed economies.

However, in the post-demographic transition era, which is the time period that characterizes our data, the rise in income due to international trade generates, at the parental level, conflicting income and substitution effects with respect to the optimal number of children and their quality. Although, according to the theory, these effects offset one another, the rise in households' income increases the relative demand for human capital intensive goods (as the subsistence agricultural consumption constraint is satisfied) and generates a force towards a decline in fertility and a rise in human capital investment in non-OECD economies as well as in OECD economies that have not reached their balanced growth path. Thus, in the postdemographic transition era, the overall effect of international trade on fertility in OECD economies would be expected to be negative, whereas the overall effect of trade on fertility in non-OECD economies is affected by two conflicting forces. Controlling for income, however, the effect of trade on fertility is predicted to be positive in non-OECD economies and negative in OECD economies. Similarly, controlling for income, the effect of trade on human capital formation is predicted to be negative in non-OECD economies and positive in OECD economies. Furthermore, some of the variation in fertility rates across countries would reflect variation in infant mortality rates. As long as parents generate utility from the number of surviving children, the theory predicts that infant mortality rates have a positive effect on fertility rates in both OECD and non-OECD economies.

\subsection{The Effect of Trade on Fertility}

Table 1 presents the outcome of linear regressions of the effects of the share of trade in GDP in 1985 on the average Total Fertility Rate in the period 1985-1990 in OECD and non-OECD countries. The regressions provide support for the hypothesis that international trade generates opposing effects on fertility rates in OECD and non-OECD economies. Columns (1) and (5) present the results from OLS regressions of average Total Fertility Rate in the period 1985-1990 on the log of the share of trade in GDP in 1985 for non-OECD and OECD economies, respectively, controlling for the log of GDP per capita in 1985. The regressions show that the signs of the association between fertility and trade are those predicted by the theory, being positive in non-OECD and negative in OECD economies, although, reflecting the potential existence of omitted variables, measurement errors, and reverse causality, these associations are statistically insignificant. Moreover, these regressions indicate that indeed our sample consists of economies in the post-demographic transition era, where fertility is negatively associated with income per capita. Consistent with the theory, this negative association is of larger magnitude and statistical significance among non-OECD economies that have experienced the onset of the demographic transition more recently. Columns (2) and (6) present the results from OLS regressions of fertility on trade for non-OECD and OECD economies, respectively, controlling for the log of GDP per capita in 1985 and for the average infant mortality rate in the period 1985-1990. The regressions show that in accordance with the theory, the association between fertility and trade is positive and significant at the 5\% level in non-OECD and negative and insignificant in OECD economies.

Once the influence of the potential existence of omitted variables, measurement errors, and reverse 
causality, is controlled for by instrumenting for the share of trade in GDP in 1985 with the Frankel-Romer instrument, then as predicted by the theory, columns (3), (4), (7) and (8) demonstrate that the effect of trade on fertility is positive and significant in non-OECD economies and negative and significant in OECD economies. Controlling for the log of GDP per capita in 1985, in column (3), and for the infant mortality rates as well, in column (4), trade has a positive effect on fertility in non-OECD economies, and this effect is significant at the $1 \%$ level. ${ }^{27}$ Moreover, as reported in column (7) and (8), trade has a negative effect on fertility in OECD economies, that is statistically significant at the $1 \%$ level if only income is controlled for, and at the $5 \%$ level if both income and infant mortality is controlled. ${ }^{28}$

Using the results in column (4) of Table 1 for non-OECD economies, the elasticity of fertility with respect to trade share is $0.70 / \mathrm{TFR}$. The average level of TFR for non-OECD countries is 4.84 and thus the elasticity is about 0.15 . Thus if a non-OECD economy doubled its trade share, then fertility would rise by $15 \%$ or by 0.7 of a child per woman. ${ }^{29}$ The same calculation for OECD economies, using the results from column (8) of Table 1, yields an elasticity of $-0.13 / 1.76=-0.07$. In this case, a doubling of trade would lead to a reduction in fertility of 0.13 of a child per woman.

Interestingly the inclusion of an instrumental variable for trade share reinforces the opposing effects of trade on fertility in OECD and non-OECD economies. For the non-OECD economies, the use of an instrumental variable increases the size and significance of the positive effect of trade on fertility, whereas for OECD economies, the use of an instrumental variable increases the size and significance of the negative effect of trade on fertility.

\footnotetext{
${ }^{27}$ Importantly, the results remain nearly identical if we exclude the control for income per capita in column (4) and (8). Namely, the overall effect of trade (directly and indirectly via income) is 0.65 (0.19) in non-OECD economies and -0.14 (0.06) for OECD economies. Moreover, the exclusion of Eastern European economies slightly increases the coefficient on trade in column (4) of Table 1 to 0.71 , which remains significant at the $1 \%$ level. The inclusion of OPEC economies slightly reduces the coefficient to 0.69 , which remains significant at the $1 \%$ level. Moreover, if the sample of non-OECD economies is restricted to the 74 countries sample used in Table 2 for the analysis of the effect of trade on education, the qualitative results remain intact. The coefficient for trade becomes .77 with a p value of 0.004 .

${ }^{28}$ The qualitative results will not be affected if the dependent variable will be based on of the average TFR over the longer time intervals 1985-1995. The point estimate on the effect of trade in non-OECD economies will be nearly identical (0.70) and the effect remains significant at the $1 \%$ level, and in OECD economies it will be -0.08 , and significant at the $10 \%$ level. The effect on the average TFR over even a longer time interval, 1985-2000, is not surprisingly weaker. It is nearly identical for non-OECD economies ( 0.68 and significant at the $1 \%$ level), and still negative, but insignificant for OECD economies. The use of the average Crude Birth Rates over the period 1985-1990 as a dependent variable does not affect the qualitative results as well. The effect of trade is positive and significant at the $1 \%$ level for non-OECD economies, and negative and significant at nearly $5 \%$ level for OECD economies.

${ }^{29}$ Note that the measure of trade is share of trade in GDP and this ranges from 13.16 (Myanmar) to 318.07 (Singapore). Thus, it is reasonable to consider a doubling of trade share.
} 
Table 1: The Effect of Trade on Total Fertility Rate

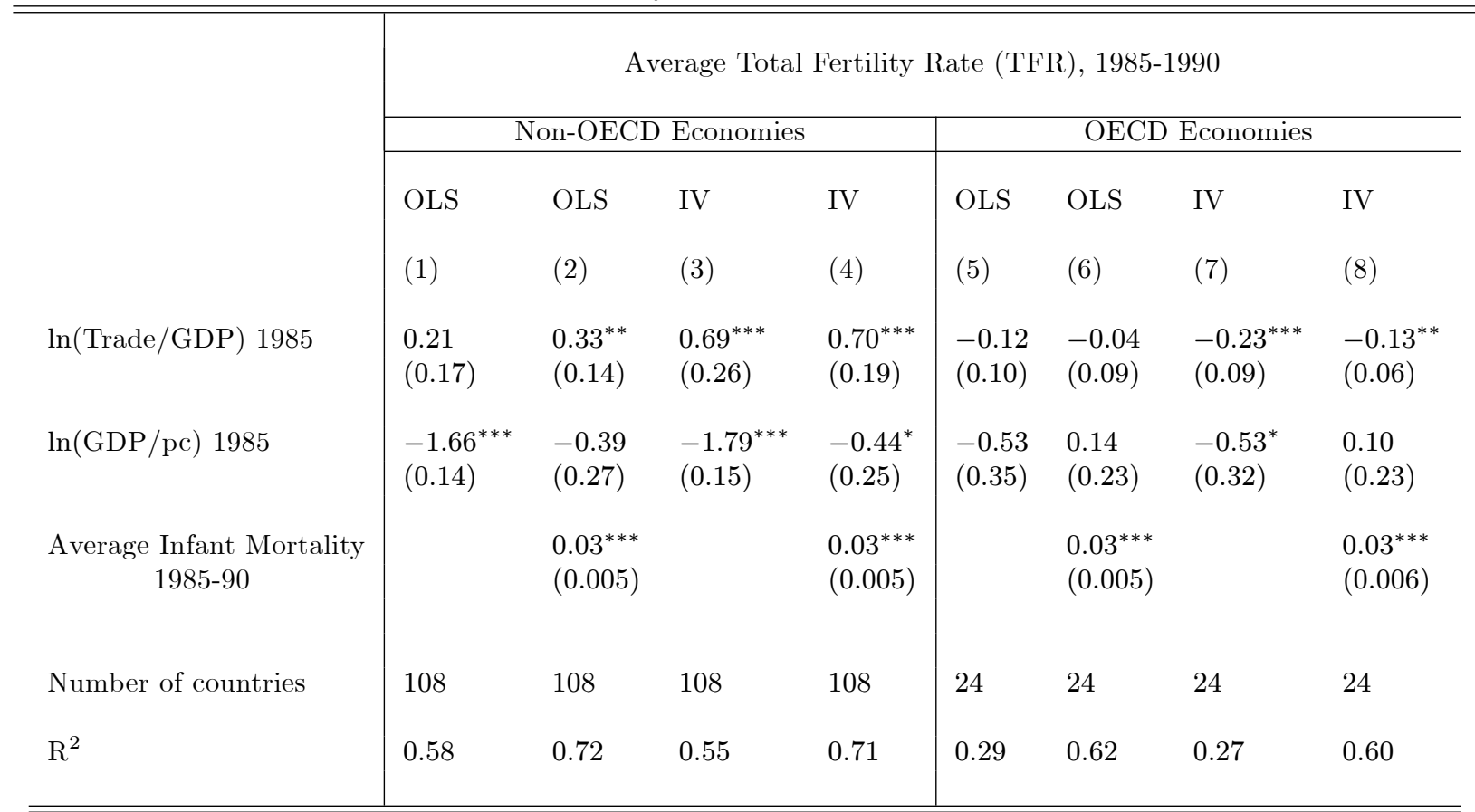

(i) Regressions (3), (4), (7) and (8) employ the Frankel-Romer IV for log of trade share in GDP in 1985

(ii) Robust standard errors in parentheses

(iii) One sided tests are performed that the coefficients on trade are of the predicted sign.

(iv) ${ }^{* * *}$ denotes significance at the $1 \%$ level ${ }^{* *}$ significance at the $5 \%$ level and ${ }^{*}$ significance at the $10 \%$ level.

The IV regressions use Frankel and Romer (1999)'s instrument for the country's intrinsic propensity to trade. This instrument is generated by aggregating the results from thousands of bilateral trade relationships which are estimated using a regression of bilateral trade share in GDP on seven variables and some of their interactions. These seven variables are the bilateral distance between the two trading economies, a dummy for whether there is a common border between the two trading economies, a dummy for whether one or more economy is landlocked and the country size variables, log area and log population for both countries. In Frankel and Romer's analysis, income per capita is the dependent variable in the final stage. They argue that the first three variables do not affect income per capita directly, only via trade, and so they exclude them from their final stage regressions. For the country size variables, they argue that these variables do have a direct effect on income per capita, via within country trade, and hence they include a country's log area and log population as exogenous variables in the final stage of their model. In our regressions, however, fertility and human capital accumulation are the dependent variables and, consistently with our theory, it appears that they will not be affected directly by the country's area or population size. ${ }^{30}$ They will be affected indirectly by these variables, via their effect on income per capita, but income is controlled for in our regression. Hence, following Frankel and Romer's reasoning, all first stage variables are excluded from the final stage regressions. ${ }^{31}$

\footnotetext{
${ }^{30}$ The data set is from the post-Malthusian era where country size does not influence fertility. Furthermore, it should be noted that even in the Malthusian steady state, fertility is unaffected by a country size.

${ }^{31}$ Although there are compelling reasons to exclude these variables from the second stage of the IV regressions, it should be noted that the qualitative results of the IV regressions (4) and (8) will not be affected by the inclusion of controls for log population in 1985 and $\log$ area. In column (4) the point estimate of the effect of log trade share in GDP in 1985 will be 2.37
} 


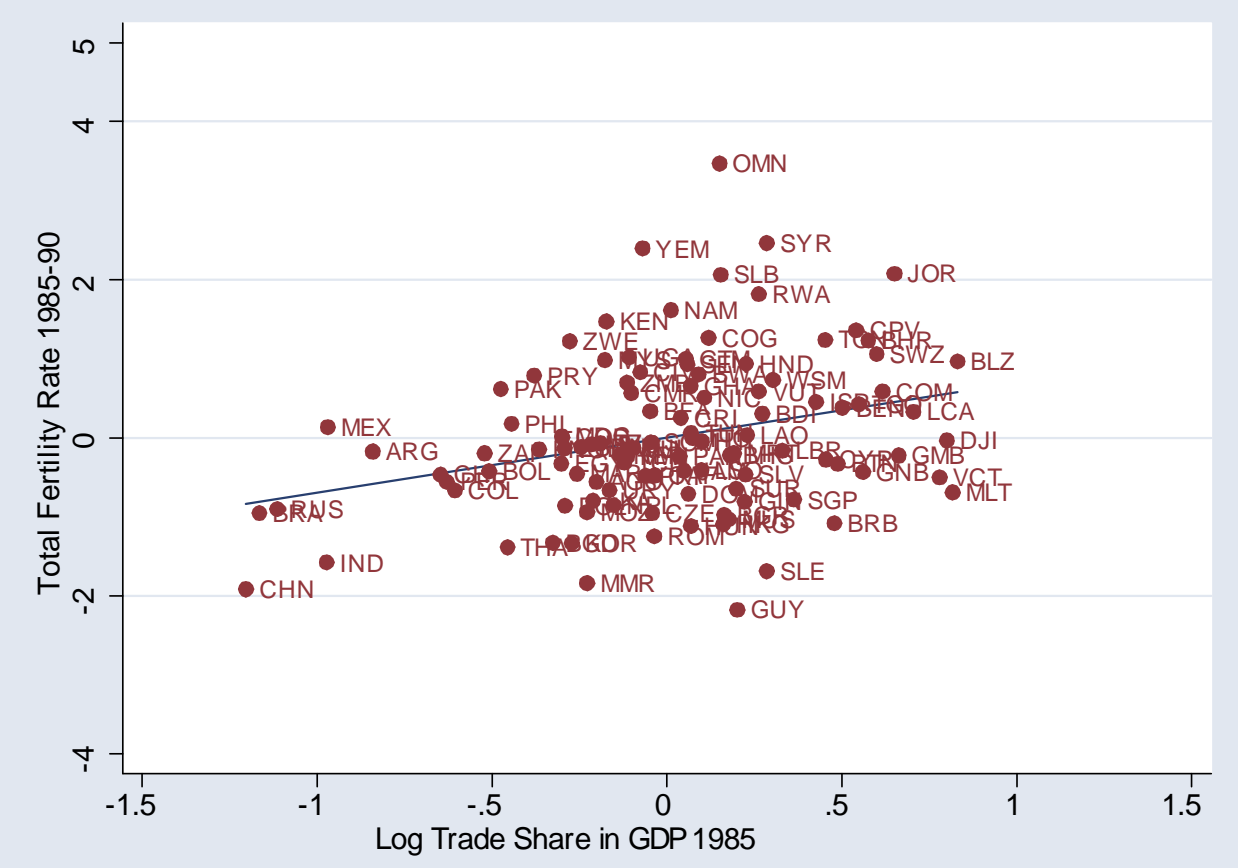

Figure 1a: The partial effect of trade on fertility in non-OECD economies

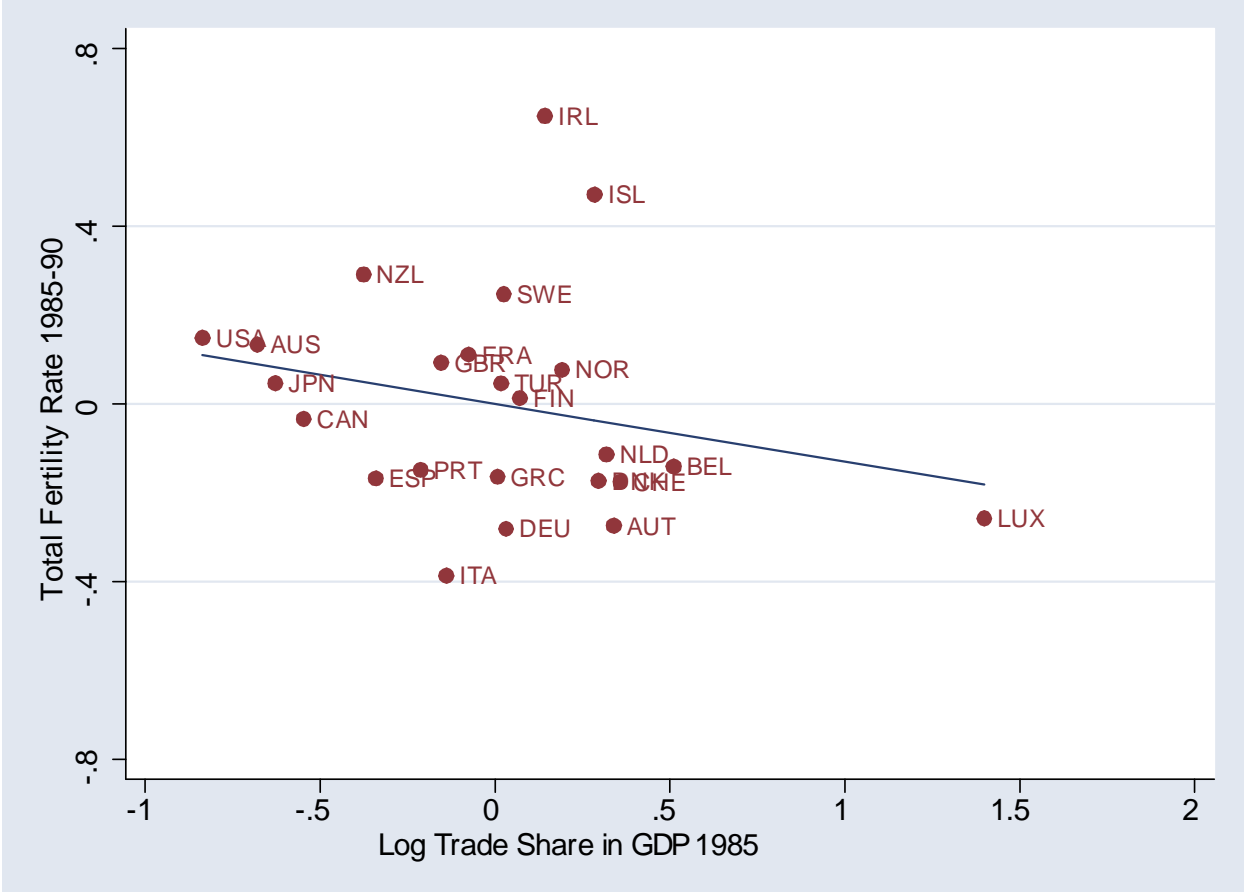

Figure 1b: The partial effect of trade on fertility in OECD economies

The main hypothesis of the theory regarding the differential effect of trade on fertility rates in developed and less developed economies is confirmed by the evidence presented in Table 1 and more formally in Table 3. The differences in the effect of trade on fertility in OECD and non-OECD economies is illustrated in Figures 1a and 1b which plot the partial effect of trade on fertility from the regressions in columns (4) (significant at the $5 \%$ level in a one sided test), whereas in column (8) it will be -0.56 (significant at the $1 \%$ level in the one-sided test). 
and (8) of Table $1 .^{32}$

\subsection{The Effect of Trade on Education}

Table 2 presents the outcome of linear regressions of the effect of the log of the share of trade in GDP in 1985 on human capital accumulation in the period 1985-1990 in OECD and non-OECD countries. These regressions provide support for the hypothesis that international trade generates opposing effects on human capital accumulation in OECD and non-OECD economies. Columns (1) and (3) present the results from OLS regressions of the change in the average years of education over the period 1985-1990 (for a population above the age of 15 ) on the log of share of trade in GDP in 1985 for non-OECD and OECD economies, respectively, controlling for the log of GDP per capita in 1985. The regressions show that the signs of the association between education and trade are those predicted by the theory, being negative in non-OECD and positive in OECD economies. Reflecting the potential existence of omitted variables, measurement errors, and reverse causality, these associations are statistically insignificant for non-OECD economies and significant only at the $10 \%$ level for OECD economies. Once the influence of the potential existence of omitted variables, measurement errors, and reverse causality is controlled for by instrumenting for the share of trade in GDP in 1985 with the Frankel-Romer instrument, then as predicted by the theory, columns (2) and (4) demonstrate that the effect of trade on education is negative and significant at the $5 \%$ level for non-OECD economies and positive and significant at the $5 \%$ level for OECD economies. ${ }^{33}$

Interestingly the inclusion of an instrumental variable for trade share reinforces the opposing effects of trade on education in OECD and non-OECD economies. For the non-OECD economies, the use of an instrumental variable increases the size and significance of the negative effect of trade on education, whereas for OECD economies, the use of an instrumental variable increases the size and significance of the positive effect of trade on education.

\footnotetext{
${ }^{32}$ It should be noted that given that only 24 countries belong to our sample of OECD economies in 1985, the significance of the negative effect of trade on fertility should be expected to be fragile to the exclusion of some countries from the sample. Nevertheless, if in Regression (7), the outliers of Luxemburg, Iceland, and Ireland are excluded together or in any feasible pairwise or individual permutation, the effect of trade remains negative and statistically significant at least at the $5 \%$ level. If in Regression (8), the outliers of Luxemburg, Iceland, and Ireland are excluded together the effect of trade remains negative and statistically significant at the $1 \%$ level. If any feasible pairwise permutation of these three countries is excluded, the results remain significant at least at the $10 \%$ level (in the one sided test). If only Luxemburg is excluded from regression (8) the effect of trade remain negative but insignificant. (If controls for $\log$ area and $\log$ population are included the significance at the $5 \%$ level is restored). However, as established in the combined sample in Tables 3, even if Luxemburg is excluded from the sample, trade has a significantly different effect on fertility in OECD and non-OECD economies.

${ }^{33}$ The qualitative results are unaffected if Eastern European economies are excluded from the sample or OPEC economies are included in it. The exclusion of Eastern European economies slightly reduces the coefficient on trade in column (2) of Table 2 to -0.26 , which remains significant at the $5 \%$ level. The inclusion of OPEC economies reduces the coefficient to -0.16 , (significant at the $1 \%$ level). Furthermore, the qualitative results will not be affected if the dependent variable will be the change in average years primary school (of the population above the age 15) over the period 1985-1990. The effect of trade on education in non-OECD economies will negative and significant at the 5\% level, and in OECD positive and significant at the $1 \%$ level in a one-sided test. Moreover, in the IV regression (2) the results will not be affected by the inclusion of the excluded control for $\log$ population in 1985. The point estimate of the effect of $\log$ trade share in GDP will become much larger in absolute value (-0.49) (significant at the $5 \%$ level). If a control for log area will be added, the effect will remain negative but insignificant. In addition, the qualitative results of the IV regression (4) will not be affected by the inclusion of the excluded control for log area. The point estimate of the effect of log trade share in GDP will become (1.08) significant at the $10 \%$ level in a one sided test). If a control for log population will be added, the effect will remain positive but insignificant. As discussed above, there are compelling reasons to exclude these variables from the second stage of the IV regressions
} 
Table 2: The Effect of Trade on Education

\begin{tabular}{|c|c|c|c|c|}
\hline & \multicolumn{4}{|c|}{ Changes in the Average Years of Education, 1985-1990 } \\
\hline & \multicolumn{2}{|c|}{ Non-OECD Economies } & \multicolumn{2}{|c|}{ OECD Economies } \\
\hline & OLS & IV & OLS & IV \\
\hline & $(1)$ & $(2)$ & $(3)$ & $(4)$ \\
\hline $\ln ($ Trade/GDP) 1985 & $\begin{array}{l}-0.10 \\
(0.08)\end{array}$ & $\begin{array}{c}-0.27^{* *} \\
(0.12)\end{array}$ & $\begin{array}{l}0.26^{*} \\
(0.19)\end{array}$ & $\begin{array}{l}0.35^{* *} \\
(0.20)\end{array}$ \\
\hline $\ln (\mathrm{GDP} / \mathrm{pc}) 1985$ & $\begin{array}{l}0.15^{* *} \\
(0.06)\end{array}$ & $\begin{array}{c}0.20^{* * *} \\
(0.07)\end{array}$ & $\begin{array}{l}-0.26 \\
(0.25)\end{array}$ & $\begin{array}{l}-0.25 \\
(0.22)\end{array}$ \\
\hline Number of countries & 74 & 74 & 23 & 23 \\
\hline $\mathrm{R}^{2}$ & 0.05 & 0.01 & 0.08 & 0.08 \\
\hline
\end{tabular}

The effect of the share of trade in GDP in 1985 on the change in the average years of total education (for population above the age 15) in the periods: 1985-1990

(i) Regressions (2) and (4) employ the Frankel-Romer IV for log of trade share in GDP in 1985

(ii) Robust standard errors in parentheses

(iii) One sided tests that the coefficients on trade are of the predicted sign.

(iv) ${ }^{* * *}$ denotes significance at the $1 \%$ level ${ }^{* *}$ significance at the $5 \%$ level ${ }^{*}$ significance at the $10 \%$ level.

The significantly different effect of trade on education in OECD and non-OECD economies which is established more formally in Table 4, is illustrated in Figures $2 \mathrm{a}$ and $2 \mathrm{~b}$ which plot the partial effect of trade on human capital accumulation from the regressions in columns (2) and (4) of Table 2. ${ }^{34}$

\footnotetext{
${ }^{34}$ Given that only 23 countries belong to our sample of OECD economies in 1985, the significance of the negative effect of trade on human capital accumulation should be expected to be fragile to the exclusion of some countries from the sample. Nevertheless, if in Regression (4), Norway, that appears to be an outlier, is excluded, the effect of trade remains positive and statistically significant at the $10 \%$ level in the one-sided test. If in addition, Finland is excluded, the effect of trade still remains positive and nearly significant at the $10 \%$ level in the one-sided test. Furthermore, as established in the combined sample in Tables 4, even if Finland and Norway are excluded from the sample, trade has a significantly different effect on education in OECD and non-OECD economies. In the non-OECD sample if two possible outliers (Zimbabwe and Pakistan) are excluded the effect of trade remains positive and statistically significant at the $5 \%$ level in the one-sided test.
} 


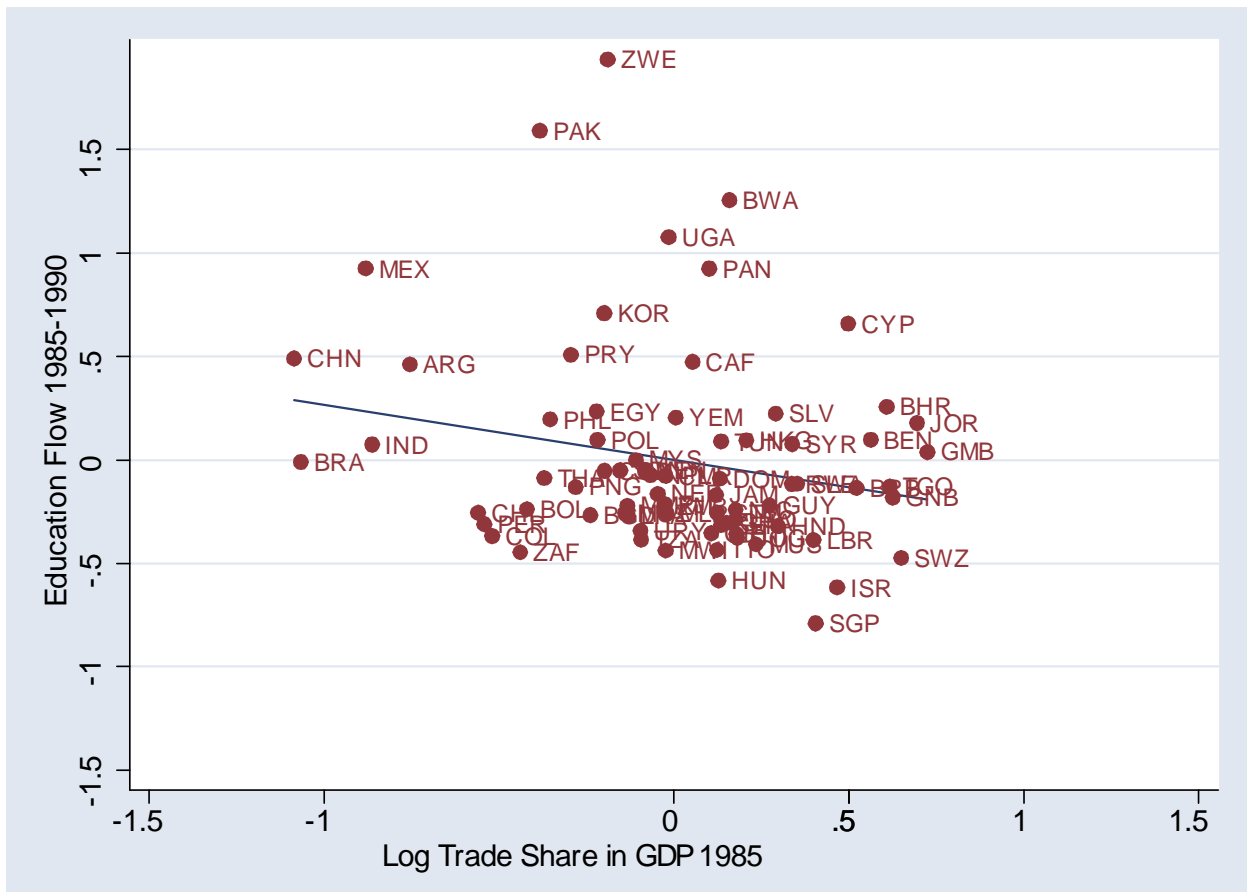

Figure 2a: The partial effect of trade on education in non-OECD economies

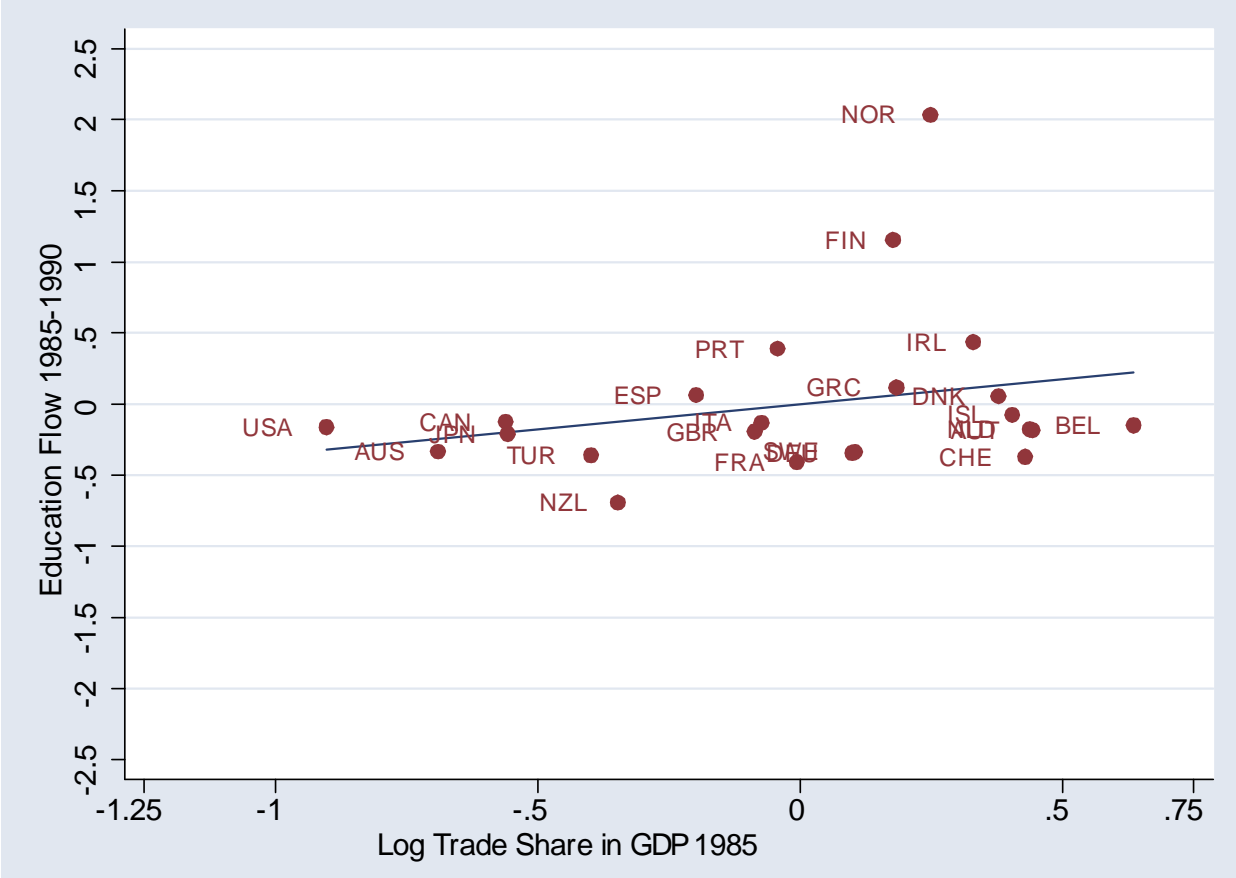

Figure 2b: The partial effect of trade on education in OECD economies

\subsection{Robustness}

\subsubsection{Robustness of the Differential Effect of Trade on Fertility}

This section confirms the hypothesis that the differential effect of trade on fertility in OECD and non-OECD economies is statistically significant and robust. Using the entire sample, it shows that the effect of trade 
on fertility is significantly more negative in OECD economies Moreover, it establishes that this differential effect of trade on fertility is robust to various changes in the regression's specification as detailed below.

The two sub-samples used in the separate regressions displayed in Table 1 can be combined into a single regression model of the form

$T F R_{i}=\beta_{0}+\beta_{1} \ln (\operatorname{tr} / G D P)_{i}+\beta_{2} \ln G D P_{i}+\beta_{3} m_{i}+\beta_{4} D_{i}+\beta_{5} D_{i} \ln (\operatorname{tr} / G D P)_{i}+\beta_{6} D_{i} \ln G D P_{i}+\beta_{7} D_{i} m_{i}+e_{i}$

Thus, $T F R_{i}$, the average Total Fertility Rate in the period 1985-1990 in economy $i$, is regressed on the country's: (a) $\log$ share of trade in GDP in 1985, $(\operatorname{tr} / G D P)_{i}$, instrumented by the Frankel-Romer instrument for trade, (b) $\log$ GDP per capita in $1985, \ln G D P_{i}$, (c) infant mortality rate in $1985, m_{i}$, (d) a dummy variable, $D_{i}$, which equals 1 if economy $i$ is an OECD economy and 0 otherwise, and (e) the interactions between the OECD dummy, $D_{i}$ and $\ln (\operatorname{tr} / G D P)_{i}, \ln G D P_{i}$ and $m_{i} \cdot{ }^{35}$ This model has the benefit of using all the information in the data set to test whether the relationship between the variables differs significantly between these two sub-samples.

Table 3 confirms the hypothesis that the differential effect of trade on fertility in OECD and nonOECD economies is statistically significant, robust and stable. Column (1) displays the results of the effect of the $\log$ of the share of trade in GDP in 1985 on the average Total Fertility Rate in the period 19851990 in the entire sample, controlling for log of GDP per capita in 1985 and the average infant mortality rate in the period 1985-1990. As predicted by the theory, this regression shows that the effect of trade on fertility is positive and significant at the $1 \%$ level in the non-OECD economies and significantly more negative in OECD economies (i.e., the coefficient on the interactions between the OECD dummy and trade is negative and significant at the $1 \%$ level). Regressions (2)-(8) demonstrates that the baseline regression (1) is remarkably robust and stable to (a) the inclusion of continental dummies, interacted with the OECD dummy (column (2)), (b) the inclusion of OPEC economies in the sample (column (3)), (c) the exclusion of Eastern European economies from the sample (column (4)), (d) the exclusion of the outlier identified in Figure 1b - Luxemburg (column (5)), (e) the replacement of the dependent variable by the average Total Fertility Rate over a longer time interval, 1985-1995 (column (6)), (f) the replacement of the dependent variable by average Total Fertility Rate over the longer period, 1985-2000 (column (7)), (g) the replacement of the dependent variable by average Crude Birth Rate in 1985-1990 (column (8)). In all these regressions, the effect of trade on fertility is positive, remarkably stable (ranging from 0.64 to 0.71), and significant at the $1 \%$ level in non-OECD economies, and is significantly more negative and very stable (ranging from -0.71 to -0.84) in OECD economies (i.e., the coefficient on the interactions between the OECD dummy and trade is negative and significant at the $1 \%$ level). ${ }^{36}$ In addition the results are nearly identical if the sample is

\footnotetext{
${ }^{35}$ The relationships estimated in this model are precisely the same as those from two separate regressions on the two subsamples, with the parameters for the separate regressions of Table 1 given by $\beta_{0}, \beta_{1}, \beta_{2}$, and $\beta_{3}$, for the subsample of non-OECD countries, and by $\beta_{0}+\beta_{4}, \beta_{1}+\beta_{5}$ and $\beta_{2}+\beta_{6}$, and $\beta_{3}+\beta_{7}$ for the subsample of OECD countries. See for example Greene (1997) Chapter 8.

${ }^{36}$ Clearly, the coefficients in regression (8) that uses Crude Birth Rates differ from those in regressions (1)-(7) that uses TFR. As discussed above, although there are compelling reasons to exclude the log area and log population from the second stage of the IV regressions, it should be noted that the qualitative results will not be affected by the inclusion of controls for $\log$ population in 1985 and $\log$ area. For instance, in the baseline regression in column (1), the effect of trade on fertility in non-OECD economies is positive and significant at the $5 \%$ level, and it is significantly more negative (at the 5\% level) for OECD economies. In Regression (2)-(7), the results remains at least significant at the $10 \%$ level. In regression (8) the results remain significant as long as Eastern European countries are excluded or continental dummies are included.
} 
restricted to the 97 countries, used in Table 4, in the baseline examination of the effect of trade on education.

Table 3. IV Regressions of the Effect of Trade on Fertility - Robustness

\begin{tabular}{|c|c|c|c|c|c|c|c|c|}
\hline \multirow{3}{*}{$\ln ($ Trade/GDP) 1985} & \multicolumn{7}{|c|}{ Total Fertility Rate } & \multirow{2}{*}{$\begin{array}{c}\text { CBR } \\
1985-90 \\
\end{array}$} \\
\hline & $1985-90$ & $1985-90$ & $1985-90$ & $1985-90$ & $1985-90$ & $1985-95$ & $1985-2000$ & \\
\hline & $\begin{array}{c}(1) \\
0.70^{* * *} \\
(0.19)\end{array}$ & $\begin{array}{c}(2) \\
0.64^{* * *} \\
(0.21)\end{array}$ & $\begin{array}{c}(3) \\
0.69^{* * *} \\
(0.19)\end{array}$ & $\begin{array}{c}(4) \\
0.71^{* * *} \\
(0.20)\end{array}$ & $\begin{array}{c}(5) \\
0.70^{* * *} \\
(0.19)\end{array}$ & $\begin{array}{c}(6) \\
0.70^{* * *} \\
(0.17)\end{array}$ & $\begin{array}{c}(7) \\
0.68^{* * *} \\
(0.16)\end{array}$ & $\begin{array}{c}(8) \\
3.49^{* * *} \\
(1.07)\end{array}$ \\
\hline $\mathrm{D}_{O E C D} \times \ln (\operatorname{Tr} / \mathrm{GDP})$ & $\begin{array}{c}-0.83^{* * *} \\
(0.20)\end{array}$ & $\begin{array}{c}-0.71^{* * *} \\
(0.24)\end{array}$ & $\begin{array}{c}-0.82^{* * *} \\
(0.20)\end{array}$ & $\begin{array}{c}-0.84^{* * *} \\
(0.21)\end{array}$ & $\begin{array}{c}-0.79^{* * *} \\
(0.21)\end{array}$ & $\begin{array}{c}-0.79^{* * *} \\
(0.18)\end{array}$ & $\begin{array}{c}-0.73^{* * *} \\
(0.18)\end{array}$ & $\begin{array}{c}-4.49^{* * *} \\
(1.23)\end{array}$ \\
\hline $\ln (\mathrm{GDP} / \mathrm{pc}) 1985$ & $\begin{array}{c}-0.44^{*} \\
(0.25)\end{array}$ & $\begin{array}{l}-0.36 \\
(0.23)\end{array}$ & $\begin{array}{c}0.03 \\
(0.23)\end{array}$ & $\begin{array}{c}-0.47^{*} \\
(0.26)\end{array}$ & $\begin{array}{c}-0.44^{*} \\
(0.25)\end{array}$ & $\begin{array}{c}-0.40^{*} \\
(0.24)\end{array}$ & $\begin{array}{c}-0.38^{*} \\
(0.22)\end{array}$ & $\begin{array}{c}-2.65^{* *} \\
(1.33)\end{array}$ \\
\hline $\mathrm{D}_{O E C D} \times \ln (\mathrm{GDP} / \mathrm{pc})$ & $\begin{array}{c}0.54 \\
(0.34)\end{array}$ & $\begin{array}{c}0.42 \\
(0.35)\end{array}$ & $\begin{array}{c}0.07 \\
(0.32)\end{array}$ & $\begin{array}{c}0.57 \\
(0.35)\end{array}$ & $\begin{array}{l}0.58^{*} \\
(0.34)\end{array}$ & $\begin{array}{l}0.67^{* *} \\
(0.31)\end{array}$ & $\begin{array}{l}0.70^{* *} \\
(0.29)\end{array}$ & $\begin{array}{l}4.90^{* *} \\
(2.05)\end{array}$ \\
\hline Infant Mortality 1985 & $\begin{array}{l}0.03^{* * *} \\
(0.005)\end{array}$ & $\begin{array}{l}0.03^{* * *} \\
(0.005)\end{array}$ & $\begin{array}{l}0.04^{* * *} \\
(0.004)\end{array}$ & $\begin{array}{l}0.03^{* * *} \\
(0.005)\end{array}$ & $\begin{array}{l}0.03^{* * *} \\
(0.005)\end{array}$ & $\begin{array}{l}0.03^{* * *} \\
(0.004)\end{array}$ & $\begin{array}{l}0.03^{* * *} \\
(0.004)\end{array}$ & $\begin{array}{c}0.19^{* * *} \\
(0.02)\end{array}$ \\
\hline $\mathrm{D}_{O E C D} \mathrm{x}$ Infant Mort & $\begin{array}{l}-0.005 \\
(0.007)\end{array}$ & $\begin{array}{l}-0.002 \\
(0.007)\end{array}$ & $\begin{array}{l}-0.011 \\
(0.007)\end{array}$ & $\begin{array}{l}-0.004 \\
(0.007)\end{array}$ & $\begin{array}{l}-0.004 \\
(0.007)\end{array}$ & $\begin{array}{l}-0.005 \\
(0.006)\end{array}$ & $\begin{array}{l}-0.006 \\
(0.006)\end{array}$ & $\begin{array}{c}0.07 \\
(0.05)\end{array}$ \\
\hline $\mathrm{D}_{O E C D}$ & $\begin{array}{l}-2.04 \\
(3.28)\end{array}$ & $\begin{array}{l}-1.87 \\
(3.27)\end{array}$ & $\begin{array}{c}1.80 \\
(3.10)\end{array}$ & $\begin{array}{l}-2.34 \\
(3.29)\end{array}$ & $\begin{array}{l}-2.52 \\
(3.28)\end{array}$ & $\begin{array}{l}-3.18 \\
(2.97)\end{array}$ & $\begin{array}{l}-3.56 \\
(2.77)\end{array}$ & $\begin{array}{c}-33.07^{*} \\
(20.00)\end{array}$ \\
\hline Continental Dummies & & Yes & & & & & & \\
\hline Including OPEC & & & Yes & & & & & \\
\hline Excluding East Euro & & & & Yes & & & & \\
\hline Excluding outliers & & & & & Yes & & & \\
\hline Number of countries & 132 & 132 & 144 & 126 & 131 & 132 & 132 & 132 \\
\hline $\mathrm{R}^{2}$ & 0.81 & 0.82 & 0.77 & 0.80 & 0.80 & 0.82 & 0.83 & 0.85 \\
\hline
\end{tabular}

The effect of the share of trade in GDP in 1985 on the average Total Fertility Rate in: 1985-90 ((1)-(5)), 1985-95 ((6)), and 1985-2000 ((7)), and on the average Crude Birth Rates (CBR), 1985-90 ((8)).

(i) All regressions employ the Frankel-Romer IV for the log of trade share in GDP in 1985.

(ii) Robust standard errors in parentheses.

(iii) One sided tests that the coefficients on trade and its interactions are of the predicted sign.

(iv) ${ }^{* * *}$ denotes significance at the $1 \%$ level ${ }^{* *}$ significance at the $5 \%$ level ${ }^{*}$ significance at the $10 \%$ level.

\subsubsection{Robustness of the Differential Effect of Trade on Education}

This section confirms the hypothesis that the differential effect of trade on education in OECD and nonOECD economies is statistically significant and robust. It shows that the effect of trade on education in the entire sample is significantly more positive in OECD economies Moreover, it establishes that this differential effect of trade on education is robust to various changes in the regression's specification as detailed below.

The two sub-samples used in the separate regressions displayed in Table 2 can be combined into a 
single regression model of the form

$$
H C_{i}=\beta_{0}+\beta_{1} \ln G D P_{i}+\beta_{2} \ln (\text { trade } / G D P)_{i}+\beta_{3} D_{i}+\beta_{4} D_{i} \ln G D P_{i}+\beta_{5} D_{i} \ln (\text { trade } / G D P)_{i}+e_{i}
$$

where $H C_{i}$ is the change in the years of education of the population, above 15, in the period 1985-1990.

Table 4 confirms the hypothesis that the differential effect of trade on education in OECD and nonOECD economies is statistically significant, robust and stable. Column (1) displays the results of the effect of the log of the share of trade in GDP in 1985 on the change in the average years of total education over the period 1985-1990 (for a population above the age of 15) for the entire sample. As predicted by the theory, the regression shows that the effect of trade on education is significantly negative in non-OECD economies and significantly more positive in OECD economies (i.e., the coefficient on the interactions between the OECD dummy and trade is positive and significant at the $1 \%$ level). Regressions (2)-(8) demonstrate that the baseline regression (1) is robust and stable to (a) the inclusion of continental dummies, interacted with the OECD dummy (column (2)), (b) the inclusion of OPEC economies in the sample (column (3)), (c) the exclusion of Eastern European economies from the sample (column (4)), (d) the exclusion of the outliers identified in Figure 2b - Norway and Finland (column (5)), (e) the replacement of the dependent variable by the change in the average years of total education over a longer time interval, 1985-1995 (column (6)), (f) the replacement of the dependent variable by the average years of total education over a longer time interval, 1985-2000 (column (7)), (g) the replacement of the dependent variable by the change in the average years of primary education, 1985-1990 (column (8)). In all these regressions, the effect of trade on education is negative and significant in non-OECD economies, and it is significantly more positive in OECD economies (i.e., the coefficient on the interactions between the OECD dummy and trade is positive and significant). ${ }^{37}$ Interestingly, the effect of trade on education is stronger over longer time intervals (1985-1995 and 19852000), reflecting the fact that the formation of human capital is time-intensive. In contrast, the effect of trade on fertility is slightly lower over longer time intervals, reflecting the faster realization of the response

\footnotetext{
${ }^{37}$ As discussed above there are compelling reasons to exclude the log area and log population from the second stage of the IV regressions. The qualitative results in the baseline regression will not be affected by the inclusion of controls for log population in 1985. If both $\log$ area and long population in 1985 are included the effect of trade on education is still negative (but insignificant) in non-OECD economies and it is still more positive in OECD economies.
} 
of fertility for economic incentives.

Table 4. IV Regressions of the Effect of Trade on Education - Robustness

\begin{tabular}{|c|c|c|c|c|c|c|c|c|}
\hline & \multicolumn{8}{|c|}{ Changes in the Average Years of } \\
\hline & \multicolumn{7}{|c|}{$\begin{array}{c}\text { Total Education } \\
\end{array}$} & \multirow{2}{*}{$\begin{array}{r}\text { Primary } \\
1985-90 \\
\end{array}$} \\
\hline & $1985-90$ & $1985-90$ & $1985-90$ & $1985-90$ & $1985-90$ & $1985-95$ & $1985-2000$ & \\
\hline & (1) & (2) & (3) & (4) & (5) & (6) & (7) & (8) \\
\hline $\ln ($ Trade/GDP) 1985 & $\begin{array}{c}-0.27^{* *} \\
(0.12)\end{array}$ & $\begin{array}{c}-0.33^{* *} \\
(0.14)\end{array}$ & $\begin{array}{c}-0.16^{*} \\
(0.13)\end{array}$ & $\begin{array}{c}-0.26^{* *} \\
(0.12)\end{array}$ & $\begin{array}{c}-0.27^{* *} \\
(0.12)\end{array}$ & $\begin{array}{c}-0.32^{* * *} \\
(0.12)\end{array}$ & $\begin{array}{c}-0.34^{* * *} \\
(0.13)\end{array}$ & $\begin{array}{c}-0.13^{* *} \\
(0.07)\end{array}$ \\
\hline $\mathrm{D}_{O E C D} \times \ln (\operatorname{Tr} / \mathrm{GDP})$ & $\begin{array}{c}0.62^{* * *} \\
(0.24)\end{array}$ & $\begin{array}{l}0.38^{*} \\
(0.26)\end{array}$ & $\begin{array}{l}0.51^{* *} \\
(0.24)\end{array}$ & $\begin{array}{c}0.61^{* * *} \\
(0.24)\end{array}$ & $\begin{array}{c}0.41^{* * *} \\
(0.17)\end{array}$ & $\begin{array}{c}0.60^{* * *} \\
(0.24)\end{array}$ & $\begin{array}{c}0.63^{* * *} \\
(0.25)\end{array}$ & $\begin{array}{c}0.21^{* * *} \\
(0.09)\end{array}$ \\
\hline $\ln ($ GDP pc) 1985 & $\begin{array}{c}0.20^{* * *} \\
(0.07)\end{array}$ & $\begin{array}{l}0.28^{* *} \\
(0.11)\end{array}$ & $\begin{array}{l}0.14^{* *} \\
(0.07)\end{array}$ & $\begin{array}{c}0.21^{* * *} \\
(0.07)\end{array}$ & $\begin{array}{c}0.20^{* * *} \\
(0.07)\end{array}$ & $\begin{array}{c}0.29^{* * *} \\
(0.07)\end{array}$ & $\begin{array}{c}0.36^{* * *} \\
(0.08)\end{array}$ & $\begin{array}{c}0.06 \\
(0.04)\end{array}$ \\
\hline $\mathrm{D}_{O E C D} \times \ln (\mathrm{GDP} / \mathrm{pc})$ & $\begin{array}{c}-0.46^{* *} \\
(0.23)\end{array}$ & $\begin{array}{l}-0.43 \\
(0.34)\end{array}$ & $\begin{array}{c}-0.40^{*} \\
(0.23)\end{array}$ & $\begin{array}{c}-0.47^{* *} \\
(0.23)\end{array}$ & $\begin{array}{c}-0.71^{* * *} \\
(0.21)\end{array}$ & $\begin{array}{c}-0.82^{* * *} \\
(0.23)\end{array}$ & $\begin{array}{c}-0.95^{* * *} \\
(0.23)\end{array}$ & $\begin{array}{c}-0.33^{* * *} \\
(0.09)\end{array}$ \\
\hline $\mathrm{D}_{O E C D}$ & $\begin{array}{c}1.37 \\
(2.66)\end{array}$ & $\begin{array}{l}1.79 \\
(2.84)\end{array}$ & $\begin{array}{l}1.36 \\
(2.65)\end{array}$ & $\begin{array}{c}1.47 \\
(2.66)\end{array}$ & $\begin{array}{l}4.43^{* *} \\
(2.07)\end{array}$ & $\begin{array}{l}4.81^{*} \\
(2.61)\end{array}$ & $\begin{array}{l}5.75^{* *} \\
(2.71)\end{array}$ & $\begin{array}{l}2.00^{* *} \\
(0.98)\end{array}$ \\
\hline Continental Dummies & & Yes & & & & & & \\
\hline Including OPEC & & & Yes & & & & & \\
\hline Excluding east. Europe & & & & Yes & & & & \\
\hline Excluding outliers & & & & & Yes & & & \\
\hline Number of countries & 97 & 97 & 104 & 95 & 95 & 96 & 96 & 97 \\
\hline $\mathrm{R}^{2}$ & 0.03 & 0.05 & 0.03 & 0.07 & 0.04 & 0.06 & 0.10 & 0.09 \\
\hline
\end{tabular}

The effect of the share of trade in GDP in 1985 on the changes in the average years of total education (for population above the age 15) in the periods: 1985-1990 ((1)-(5)), 1985-1995 ((6)), and 1985-2000 ((7)), and on the changes in average years of primary education, 1985-1990 ((8)).

(i) All regressions employ the Frankel-Romer IV for the log of trade share in GDP in 1985.

(ii) Robust standard errors in parentheses.

(iii) One sided tests that the coefficients on trade and its interactions are of the predicted sign.

(iv) ${ }^{* * *}$ denotes significance at the $1 \%$ level ${ }^{* *}$ significance at the $5 \%$ level ${ }^{*}$ significance at the $10 \%$ level.

\section{Historical Evidence}

Historical evidence indicates that the fundamental hypothesis of this research is consistent with the process of development of the last two centuries and in particular with the diverging experience in terms of the levels of income per capita and population growth rates of the UK and India since the nineteenth century. The historical evidence described in this section suggests that indeed the asymmetric effect of international trade on the timing of the demographic transition in developed and less-developed economies, and its persistent effect, therefore, on the initial patterns of comparative advantage may be an important element behind the Great Divergence over the last two centuries.

The historical analysis highlights in particular the contrasting process of development of the UK and 
India over the last two centuries. The evidence demonstrates that during the nineteenth century the UK traded manufactured goods for primary products with India. ${ }^{38}$ Consistent with the proposed hypothesis, industrialization in India regressed over this century whereas industrialization in the UK accelerated. The process of industrialization in the UK led to a significant increase in the demand for skilled labor in the second phase of the industrial revolution, triggering a demographic transition and a transition to a state of sustained economic growth. In India, in contrast, the lack of demand for skilled labor delayed the demographic transition and the process of development. Thus, while the gains from trade were utilized in the UK primarily towards an increase in output per capita, in India they were more biased towards an increase in the size of the population. ${ }^{39}$

\subsection{North-South Trade and Industrialization}

Consistent with the main hypothesis of this research, during the 19th century, North-South trade, as well as North-North trade, expanded significantly due to a rapid industrialization in Northwest Europe as well as to the reduction of trade barriers and transportation costs and the benefits of the gold standard. The ratio of world trade to output was about $2 \%$ in 1800 , but then it rose to $10 \%$ in 1870 , to $17 \%$ in 1900 and $21 \%$ in 1913 (Estavadeordal, Frantz and Taylor, 2002). While much of this trade occurred between industrial economies a significant proportion was between industrial and non-industrial economies. As shown in Table 5, before 1900 nearly 50\% of manufactured exports were to non-European and non-North American economies and by the end of 19th Century a clear pattern of specialization had emerged. The UK and Northwest Europe were net importers of primary products and net exporters of manufactured goods, whereas the exports of Asia, Oceania, Latin America and Africa were overwhelmingly composed of primary products. (Findlay and O'Rourke, 2001).

Atlantic trade as well as trade with Asia, in an era of colonialism, had major effects on European growth starting in the late 16th century (Acemoglu et al., 2005). Furthermore, later expansion of international trade benefited and contributed further to the process of industrialization in the UK and Europe (Mokyr, 1985; Crafts and Thomas, 1986; O'Rourke and Williamson, 1999). For the UK, the proportion of foreign trade to national income grew from about $10 \%$ in the 1780 's to about $26 \%$ in the period $1837-45$, and $51 \%$ in the period 1909-13 (Kuznets, 1967). Other European economies experienced a similar pattern as well. The proportion of foreign trade to national income on the eve of World War I was 54\% in France, $38 \%$ in Germany , 34\% in Italy, and 40\% in Sweden (Kuznets, 1967). Furthermore, exports were critical for the viability of some industries, especially the cotton industry, where $70 \%$ of the UK output was exported in the 1870's (Mokyr, 1989). Thus while technological advances could have spawned the industrial revolution without an expansion of international trade, the growth in exports increased the pace of industrialization and the growth rate of output per capita. Moreover, Pomeranz (2000), provides historical evidence for the

\footnotetext{
${ }^{38}$ The theory is compatible with the case in which the patterns of specialization are not determined by market forces but rather by the interaction between colonial forces and international trade. Colonialism reinforced the adverse effect of international trade on the process of industrialization of less developed economies, depressing the demand for human capital and enhancing the incentive to convert the gains from trade into population growth rather than into an increase in output per capita.

${ }^{39}$ Consistent with the viewpoint that trade has not been uniformly beneficial across time and regions, recent research has indicated that the relationship between openness and growth changed in the last century. For example Clemens and Williamson (2004) and Vamvakadis (2002) find a negative relationship between openness and growth for the period 1870-1913 and a negative relationship for the period 1970-1998.
} 
vital role of trade in the 'take off' of the European economies. He argues that technological and development differences between Europe and Asia were minor around 1750, but the discovery of the New World enabled Europe, via Atlantic trade, to overcome 'land constraints' and to take-off technologically. ${ }^{40}$

Non-industrialized economies were an important market for the export of the industrial economies, as exhibited in Table 5. Trade with Asia was especially significant for Britain. According to Bairoch (1974) trade with Asia constituted over $20 \%$ of UK total exports throughout the nineteenth century. In contrast, trade with Asia was only 5\% or less of French, German or Italian exports. UK imports from Asia were also much more important for the UK than for Europe. Bairoch estimates that $23 \%$ of UK imports were originated in Asian countries in 1860 as compared with $12 \%$ for continental Europe.

Table 5. Regional Shares of World Trade in Manufactures

\begin{tabular}{|c|c|c|c|c|c|c|}
\hline & \multicolumn{2}{|c|}{$1876-1880$} & \multicolumn{2}{|c|}{$1896-1900$} & \multicolumn{2}{|c|}{1913} \\
\hline & Exports & Imports & Exports & Imports & Exports & Imports \\
\hline U.K. and Ireland & $37.8 \%$ & $9.1 \%$ & $31.5 \%$ & $10.4 \%$ & $25.3 \%$ & $8.2 \%$ \\
\hline Northwest Europe & $47.1 \%$ & $18.1 \%$ & $45.8 \%$ & $20.3 \%$ & $47.9 \%$ & $24.4 \%$ \\
\hline Other Europe & $9.2 \%$ & $13.3 \%$ & $10.3 \%$ & $12.2 \%$ & $8.3 \%$ & $15.4 \%$ \\
\hline U.S. and Canada & $4.4 \%$ & $7.7 \%$ & $7.4 \%$ & $9.6 \%$ & $10.6 \%$ & $12.1 \%$ \\
\hline Rest of the World & $1.5 \%$ & $51.8 \%$ & $5.0 \%$ & $47.5 \%$ & $7.9 \%$ & $39.9 \%$ \\
\hline
\end{tabular}

Source:Yates (1959).

For India, however, international trade played the reverse role. As Chaudhuri (1983) describes, 18131850 was a period of a rapid expansion in the volume of exports and imports which gradually transformed India from being an exporter of manufactured products - largely textiles - into a supplier of primary commodities. Trade with the UK was fundamental in this process, as Table 6 demonstrates, with the UK supplying over two thirds of its imports for most of the nineteenth century and being the market for over a third of its exports. Bairoch's $(1974,1982)$ analysis of international levels of industrialization and international trade supports the viewpoint that international trade was associated with a decrease in the per capita level of industrialization in India.

Table 6. Share of the Value of British Trade in Total Value of Indian Trade

\begin{tabular}{l|c|c|c|c|c|c|c|c}
\hline \hline & $1828-9$ & $1839-40$ & $1850-1$ & $1860-1$ & $1880-1$ & $1900-1$ & $1920-1$ & $1940-1$ \\
\cline { 2 - 9 } Exports & $48.2 \%$ & $57.1 \%$ & $44.6 \%$ & $43.1 \%$ & $41.6 \%$ & $29.8 \%$ & $22.1 \%$ & $34.7 \%$ \\
Imports & $65.0 \%$ & $75.7 \%$ & $72.1 \%$ & $84.8 \%$ & $82.9 \%$ & $65.6 \%$ & $60.9 \%$ & $22.9 \%$ \\
\hline
\end{tabular}

Source: Chaudhuri (1983).

As Table 7 suggests, the rapid industrialization in the UK in the nineteenth century was associated with a decline in the per capita level of industrialization in India. Furthermore, Bairoch (1974) found that industries that employed new technologies made up between 60 and 70 percent of the UK manufacturing

\footnotetext{
${ }^{40}$ Clark and Feenstra (2001) establish that most of the Great Divergence occurred in the last two centuries and it is originated by differences in labor efficiency across countries. Moreover, they argue that international trade patterns reflected these differences in labor efficiency.
} 
industry in 1860 but less than 1 percent of manufacturing industries in the developing countries.

Table 7. Per Capita Industrialization Levels

\begin{tabular}{c|c|c|c|c|c}
\hline \hline & 1800 & 1860 & 1913 & 1953 & 1980 \\
UK & 16 & 64 & 115 & 210 & 325 \\
Europe & 8 & 17 & 45 & 90 & 267 \\
India* & 6 & 3 & 2 & 5 & 16 \\
\hline \multicolumn{5}{l}{ Source: Bairoch (1982) }
\end{tabular}

The index is normalized to 100 for the UK in 1900

India is measured using its boundaries in 1913

\subsection{Industrialization and Human Capital Accumulation}

The process of industrialization in the UK was characterized by a gradual increase in the relative importance of human capital accumulation. In the first phase of the Industrial Revolution (1760-1830), capital accumulation as a fraction of GNP increased significantly whereas literacy rates remained largely unchanged. Skills and literacy requirements had been minimal and the state devoted virtually no resources to raise the level of literacy of the masses, and economic growth was not impeded by educational retardation. Workers developed skills primarily through on-the-job training, and child labor was highly valuable. Consequently, literacy rates had not increased during the period 1750-1830. The requirements for technical skills in that period, were slight and adequately met by traditional means (Galor, 2005).

In the second phase of the industrial revolution, industrialization caused an increase in the demand for human capital by the industrial sector. ${ }^{41}$ Capital accumulation subsided, the education of the labor force markedly increased and skills became necessary for production. The investment ratio increased from 6 percent in 1760 to 11.7 percent in the year 1831, but it remained around $11 \%$ on average in the period 1856-1913 (Crafts, 1985; Matthews et al., 1982). ${ }^{42}$ In contrast, the second half of the nineteenth century was marked by a great expansion of education in the UK. The average years of schooling of the male labor force of England which did not change significantly until 1830s, tripled by the beginning of the twentieth century (Matthews et al., 1982) and school enrollment at the age of 10 increased from $40 \%$ in 1870 to $100 \%$ in 1900. This increase in human capital investment was in part a response to an increase in demand for skilled labor by industrialists. The British government responded to this demand by setting up in 1868 the Parliamentary Select Committee on Scientific Education which lead to the 1870 Education Act and the 1902 Balfour Act - the education reform in England that marked the consolidation of a national education system and the creation of a publicly supported secondary school system. A similar pattern occurred in other European countries as well as in the USA and Canada (Galor, 2005).

\footnotetext{
${ }^{41}$ Hence the lack of non-controversial evidence about the increase in the return to skilled labor in the second phase of the industrial revolution should not raise doubts about the validity of the proposed mechanism. The increased demand for human capital has not resulted necessarily in an increase in the return to human capital due to a significant increase in the supply of skilled workers that was generated by institutional changes (e.g., the provision of public education) that lowered the cost of investment in human capital and by the increase in the incentive for investment in education.

42 The emergence of human capital as a prime engine of economic growth in the second phase of the Industrial Revolution, channeled resources towards investment in human capital as well as investment in physical capital. Consequently, although aggregate investment in human and physical capital had increased, measured saving rates (where national accounts consider investment in education as expenditure) remained constant.
} 
Education was not expanded to a similar degree in India in the 19th Century. As noted by Basu (1974), during the nineteenth century the state of education in India was characterized by a relatively large university sector, aimed at producing skilled bureaucrats rather than industrialists, alongside widespread illiteracy of the masses. The literacy rate was very low, (e.g., 10\% in Bengal in 1917-8) but nevertheless, attempts to expand primary education in the twentieth century were hampered by poor attendance and high drop out rates, which may suggest that the effective rate of return to education was relatively low. The lack of broad based education in India can also be seen using the data of Barro and Lee (2000). Despite an expansion of education throughout the twentieth century Barro and Lee report that in 196072.2 percent of Indians aged 15 and above had "no schooling" compared with 2 percent in the UK.

\subsection{Industrialization, Population Growth and the Demographic Transition}

For the major part of human existence economies appear to have been in a state of Malthusian stagnation. Diminishing returns to labor along with a positive effect of the standard of living on the growth rate of population provided a self equilibrating role for the size of the population in a stationary economic environment. Changes in the technological environment or in the availability of land led to larger but not richer population. The growth rate of output per capita had been negligible over time and the standard of living had not differed greatly across countries.

The emergence from Malthusian stagnation in Europe as a whole was initially very slow, (Maddison, 2001). During this slow transition, the Malthusian mechanism linking higher income to higher population growth continued to function, but the reduction in resources per capita caused by higher population was counteracted by technological progress, which allowed per capita income to keep rising. The average growth of output per capita over the period 1820-1870 rose to an annual rate of 1.0 percent along with an impressive increase in education. During this time interval, fertility rates increased in most of Western Europe until the second half of the nineteenth century. Furthermore, the acceleration in technological progress increased the return to human capital and ultimately triggered a demographic transition in which fertility rates declined rapidly, paving the way to an era of sustained economic growth. The level of resources invested in each child increased and population growth fell, bringing about a sustained average annual increase in income per capita of about two percent over the period 1929-1990 (Galor, 2005).

The evolution of population in the UK and India was characterized by these three distinct phases as well. In the Malthusian phase population increased but income per capita remained roughly constant, in the early take-off the growth of income per capita and population increased, and in the modern stage a demographic transition took place and the rate of population growth falls while income per capita rises. In the UK, population growth increased rapidly during the industrial revolution before declining sharply in the twentieth century. In contrast India has not until recently experienced a rapid increase in industrialization and has seen population growth increase with income in a Malthusian manner. This delay in the demographic transition in India lead, according to the proposed theory, to the divergence between UK and India. 


\section{Concluding Remarks}

This research suggests that the transformation in the distribution of income and population across the globe that accompanied the take-off from an epoch of stagnation to sustained economic growth is partly associated with the contrasting effects of international trade on the timing of the demographic transition in industrial and non-industrial countries. In industrial economies international trade has enhanced the specialization in the production of skilled intensive goods and stimulated technological progress. The rise in the demand for skilled labor has induced an investment in the quality of the population, expediting the demographic transition, stimulating technological progress and further enhancing the comparative advantage of these industrial economies in the production of skilled intensive goods. In non-industrial economies, in contrast, the specialization in the production of unskilled intensive goods that has been triggered by international trade has reduced the demand for skilled labor, providing limited incentives to invest in population quality. The demographic transition has been therefore delayed, increasing further the abundance of unskilled labor in these economies and enhancing their comparative disadvantage in the production of skilled intensive goods. International trade has therefore widened the gap between the technological level as well as the skill abundance of industrial and non-industrial economies, enhancing the initial patterns of comparative advantage and generating sustained differences in income per capita across countries.

The asymmetric effect of international trade on the timing of the demographic transition in developed and less-developed economies, and its persistent effect, therefore, on the initial patterns of comparative advantage, may suggest that the rapid transition of the currently developed economies into a state of sustained economic growth is associated with the slow transition of less developed economies into a state of sustained economic growth.

The analysis abstracts from several factors that are relevant for the assessment of the effects of international trade on population growth and the process of development in less developed economies. Cultural and institutional differences between countries in the determination of population growth, in the provision of public education, and in the process of technological change would be reflected in the demographic characteristics and in the patterns of comparative advantage. Moreover, the adverse effect of international trade on industrialization and thus on the timing of the demographic transition could have been mitigated by the positive effect of trade on technological diffusion across countries. Nevertheless, labor productivity greatly differs across countries and even among industries in which technologies are very similar. Moreover, since the rate of technological diffusion depends upon the appropriateness of factor endowments in the receiving country, the adverse effect of trade on the factor endowment of less developed economies would slow down the rate of technological diffusion. ${ }^{43}$

In contrast to the existing literature on the dynamics of comparative advantage, the focus on the interaction between population growth and comparative advantage and the persistent effect that this interaction may have on the distribution of population and income in the world economy generates an important new

\footnotetext{
${ }^{43}$ The effect of trade on technological diffusion is discussed by Findlay (1996). The imperfections in this process are illustrated for instance by Clark (1987) who shows that despite the fact that in 1910 textile machinery was uniform around the world, labor productivity was ten times higher in advanced countries than in the less developed ones. This imperfection may be related to the effect of factor endowments on the adoption of technologies (Basu and Weil, 1998); Zeira, 1998; Acemoglu and Zilibotti, 2001).
} 
insight regarding the distribution of the gains from trade. The theory suggests that even if trade between developed and less developed economies equalizes output growth in the trading countries, income per capita of developed and less developed economies will diverge, since in developed economies the growth of total output will be generated primarily by an increase in output per capita, whereas in less developed economies the contribution of population growth to the growth of total output will be more significant.

In accordance with the theory, cross country regression analysis supports the hypothesis that international trade generates opposing effects on fertility rates and education in developed and less developed economies. It demonstrates that international trade has a positive effect on fertility and a negative effect on human capital formation in non-OECD economies, whereas in OECD economies, trade triggers a decline in fertility and an increase in human capital accumulation. Thus, international trade accentuates the initial patterns of comparative advantage and is likely to affect differently the growth trajectory of population, human capital, and income per capita of developed and less developed economies. 


\section{Appendix: Summary Statistics and Data Sources}

Table A1. Summary Statistics

\begin{tabular}{|c|c|c|c|c|}
\hline \multirow[b]{3}{*}{ Average Total Fertility Rate 1985-1990 } & \multicolumn{2}{|c|}{ Non-OECD Economies } & \multicolumn{2}{|c|}{ OECD Economies } \\
\hline & Observations & Mean & Observations & Mean \\
\hline & 108 & 4.84 & 24 & 1.76 \\
\hline Average Total Fertility Rate 1985-1995 & 108 & 4.65 & 24 & 1.75 \\
\hline Average Total Fertility Rate 1985-2000 & 108 & 4.46 & 24 & 1.72 \\
\hline Average Crude Birth Rate 1985-1990 & 108 & 35.18 & 24 & 13.56 \\
\hline Average Infant Mortality Rate 1985-1990 & 108 & 70.06 & 24 & 10.89 \\
\hline Average years of schooling 1985 & 74 & 4.18 & 23 & 8.28 \\
\hline Average year of schooling 1990 & 76 & 4.57 & 23 & 8.75 \\
\hline Average year of schooling 1995 & 73 & 4.97 & 23 & 9.13 \\
\hline Average year of schooling 2000 & 73 & 5.22 & 23 & 9.40 \\
\hline Average years of primary schooling, 1985 & 74 & 3.06 & 23 & 5.04 \\
\hline Average years of primary schooling, 1990 & 76 & 3.27 & 23 & 5.14 \\
\hline Log GDP Per Capita 1985 & 108 & 7.49 & 24 & 9.28 \\
\hline Log Trade Share in GDP 1985 & 108 & 4.09 & 24 & 4.16 \\
\hline Log Propensity to Trade (Frankel-Romer IV) & 108 & 2.97 & 24 & 2.90 \\
\hline
\end{tabular}

Crude Birth Rate - The number of births per 1,000 population,.estimated for the five-year intervals, 19851990. Source: UN Population Division: http://esa.un.org/unpp/.

Total Fertility Rate - The average number of children a hypothetical cohort of women would have at the end of their reproductive period if they were subject during their whole lives to the fertility rates of a given period and if they were not subject to mortality. It is expressed as children per woman, estimated for the five-year intervals: 1985-1990, 1990-1995, 1995-2000. Source: UN Population Division: http://esa.un.org/unpp/.

Infant mortality rate - The probability of dying between birth and exact age 1 . It is expressed as deaths per 1,000 births, estimated for the five-year intervals 1985-1990. Source: UN Population Division: http://esa.un.org/unpp/.

Frankel-Romer instrument - Intrinsic propensity to trade in 1985 for countries in the world. Source: Frankel and Romer (1999).

Share of Trade in GDP in 1985. Source: Frankel and Romer (1999). Also available from Penn World Tables Mark 5.6, series OPEN.

Log GDP per capita 1985. Source: Penn World Tables Mark 5.6, series RGDPCH.

Average years of schooling in the total population aged 15 and above. Source: Barro Lee (2000).

Average years of primary schooling in the total population aged 15 and above. Source: Barro Lee (2000).

OECD. - Economies that were members of the OECD in 1985 and are also part of the Frankel Romer data set. They are: Australia, Austria, Belgium, Canada, Denmark, Finland, France, Germany, Greece, Iceland, Ireland, Italy, Japan, Luxembourg, Netherlands, New Zealand, Norway, Portugal, Spain, Sweden, Switzerland, Turkey, United Kingdom and United States of America.

Eastern European Countries - These are economies that were in Eastern Europe in1985 and are also part of the Frankel Romer data set. They are: Bulgaria, Czech Republic, Hungary, Poland, Romania. 
$O P E C$ - . Economies that were members of OPEC in 1985 and are also part of the Frankel Romer data set. They are: Algeria, Ecuador, Gabon, Indonesia, Iran (Islamic Republic of), Iraq, Kuwait, Nigeria, Qatar, Saudi Arabia, United Arab Emirates, Venezuela.

\section{Appendix B}

Lemma A1 In the Malthusian stage, if technology is stationary, there exists a unique locally stable steady state level of population if (i) $(1-\alpha-\beta) / \tau^{u}>1$, (ii) $\gamma>\left[(1-\alpha-\beta)-(1-\alpha) \tau^{u}\right] /\left[(1-\alpha-\beta)+(1-\alpha) \tau^{u}\right]$, and (iii) $N_{0}<\left(a_{0}^{a} / \widetilde{c}\right)^{1 /(1-\gamma)}$.

Proof. As follows from Lemma 2 and the individual's optimization problem, the population dynamic in the Malthusian stage is

$$
N_{t+1}=\left\{\begin{array}{lll}
\frac{(1-\alpha-\beta)}{(1-\alpha) \tau^{u}}\left[1-\left(\frac{\widetilde{c}}{a_{t}^{a}}\right)^{\frac{1}{\gamma}} N_{t}^{\frac{1-\gamma}{\gamma}}\right] N_{t} & \text { if } \quad \alpha \frac{w_{t}^{u}}{p_{t}}<\widetilde{c} \\
\frac{(1-\alpha-\beta)}{\tau^{u}} N_{t} & \text { if } & \alpha \frac{w_{t}^{u}}{p_{t}} \geq \widetilde{c}
\end{array}\right.
$$

Condition (i) of the Lemma ensures that when agents are unconstrained and are rearing only unskilled children, the population is rising. Noting the properties of the old agricultural production technology (1), the economy will eventually reach a state where its agents are constrained by the subsistence constraint. The steady state value of $N$, is

$$
\bar{N}=\left(\frac{\widetilde{c}}{a_{t}^{a}}\right)^{\frac{1}{\gamma-1}}\left[1-\frac{(1-\alpha) \tau^{u}}{(1-\alpha-\beta)}\right]^{\frac{\gamma}{1-\gamma}} .
$$

It is locally stable since as follows from condition (ii):

$$
\left.\frac{d N_{t+1}}{d N_{t}}\right|_{N_{t+1}=N_{t}}=\frac{(1-\alpha-\beta)}{(1-\alpha) \tau^{u}}\left\{1-\frac{1}{\gamma}\left[1-\frac{(1-\alpha) \tau^{u}}{(1-\alpha-\beta)}\right]\right\} \in(-1,1),
$$

provided, as guaranteed by condition (iii), that the initial level of population is sufficiently small so as to assure that the initial average product of labor is not below the subsistence level.

\section{Proof of Lemma 4.}

(a) Follows from (A1), (A2) and Lemma 3, noting that $g(0)>0$.

(b) Lemma A1 shows that under the old technology the unskilled wage, $a_{t}^{a}\left(L_{0}^{a, 0}\right)^{\gamma-1}$, tends to the constant level of $\widetilde{c}(1-\alpha-\beta) /\left[(1-\alpha-\beta)-(1-\alpha) \tau^{u}\right] \equiv \tilde{w}^{u}$. However since $A_{t}^{a}$ is rising over time, there exits a time period $\left(t^{a}\right)^{*}$ such that, $A_{t}^{a}>a_{t}^{a}\left(L_{0}^{a, 0}\right)^{\gamma-1}$. For $\left(t^{a}\right)^{*}<t<\left(t^{m}\right)^{*}$ it follows from (13) that the population will be higher than it would have been in the Malthusian regime. Therefore the shadow Malthusian unskilled wage given by $a_{t}^{a}\left(\left(L_{t}^{a, 0}\right)^{*}\right)^{\gamma-1}$ will be below the level $\tilde{w}^{u}$. (where $\left(L_{t}^{a, 0}\right)^{*}$ is the level of employment in the old agricultural sector necessary for the old agricultural sector alone to satisfy the total demand for agricultural products at time $t)$. In contrast, $A^{a}$ will continue to rise. Thus $A_{t}^{a} / a_{t}^{a}>\left(\left(L_{t}^{a, 0}\right)^{*}\right)^{\gamma-1}$ still holds. For $\left(t^{m}\right)^{*}<t<\left(t^{m}\right)^{* *}$, where $\left(t^{m}\right)^{* *}$ is the start of the modern industrial stage, $A_{t}^{a} / a_{t}^{a}>\left(\left(L_{t}^{a, 0}\right)^{*}\right)^{\gamma-1}$ still holds since the demand for agricultural goods will be at least as high as it would have been without any new technologies, and thus the shadow Malthusian unskilled wage will be below the level $\tilde{w}^{u} .44$ Finally, for $t>\left(t^{m}\right)^{* *}$, the demand for agricultural goods will be growing at the rate of growth of $A_{t}^{a}$, which is a greater rate than would be occurring under the Malthusian system. Thus again the shadow Malthusian unskilled wage will be below the level $\tilde{w}^{u}$ and $A_{t}^{a} / a_{t}^{a}>\left(\left(L_{t}^{a, 0}\right)^{*}\right)^{\gamma-1}$ still holds.

\section{Proof of Lemma 5.}

\footnotetext{
${ }^{44}$ For some parameter specifications the fall in fertility caused by the introduction of the new industrial technology may reduce fertility so much and for so long that the population falls below the level it would have attained if the economy had continued on its Malthusian path without the new technologies. If this occurs then we cannot rule out the possibility that $a_{t}^{a}\left(\left(L_{t}^{a, 0}\right)^{*}\right)^{\gamma-1}$ rises above $A^{a}$. We regard this as a highly unlikely and very counter factual. Based on McEvedy and Jones's (1978), the population of the British Isles grew from 5 million in 1500 to 10 million in 1750 . If growth continued at this rate then the current population of the British Isles would have been 20 million, much below its current actual level of approximately 60 million. Hence, the underlying assumption implies that the population at the beginning of the modern industrial stage is greater than it would have without the existence of the new production technologies.
} 
(i) If $Y_{t+1}^{m, N}=0$, it follows from (14) that $w_{t+1}^{s} / w_{t+1}^{u}=0<\tau^{s} / \tau^{u}$ and $n_{t}^{i, s}=0$ for all $i$. Hence, $h_{t+1}=0$.

(ii) If $Y_{t+1}^{a, N}>0$ and $Y_{t+1}^{m, N}>0$ then $w_{t+1}^{s} / w_{t+1}^{u}=\tau^{s} / \tau^{u}$ and $n_{t}^{i, s}>0$, for some $i$, and $h_{t+1}>0$. Let $N_{t}^{A}$ and $N_{t}^{M}$ be the number of unskilled individuals employed in the agricultural and the manufacturing sector in period $t$, respectively, and let $H_{t}$ be the number of skilled individuals employed in the manufacturing sector in period $t$. Hence, $N_{t}^{A}+N_{t}^{M}+H_{t}=N_{t}$, where $N_{t}$ is the number of individuals in the working generation. Let $l_{t}^{u}$ and $l_{t}^{s}$ be the labor supply of unskilled and skilled individuals, respectively. It follows that the amount of unskilled labor employed in the agricultural and the manufacturing sectors is $L_{t}^{a, N}=l_{t}^{u} N_{t}^{A}$ and $L_{t}^{m, N}=l_{t}^{u} N_{t}^{M}$, respectively, and the amount of skilled labor employed in the manufacturing sector is $H_{t}^{m}=l_{t}^{s} H_{t}$, where noting (13), and that $A_{t}^{a}=A\left(\lambda_{t}\right)$,

$$
\begin{aligned}
& l_{t}^{u}=\left\{\begin{array}{cc}
{[\beta /(1-\alpha)]+[(1-\alpha-\beta) /(1-\alpha)] \widetilde{c} / A_{t}^{a} \equiv l^{u}\left(\lambda_{t}\right)} & \text { if } \quad \alpha w_{t}^{u} / p_{t}<\widetilde{c} \\
\alpha+\beta & \text { if } \quad \alpha w_{t}^{u} / p_{t} \geq \widetilde{c}
\end{array}\right. \\
& l_{t}^{s}=\left\{\begin{array}{cc}
{[\beta /(1-\alpha)]+\left(\tau^{u} / \tau^{s}\right)[(1-\alpha-\beta) /(1-\alpha)] \widetilde{c} / A_{t}^{a} \equiv l^{s}\left(\lambda_{t}\right)} & \text { if } \alpha w_{t}^{s} / p_{t}<\widetilde{c} \\
\alpha+\beta & \text { if } \alpha w_{t}^{s} / p_{t} \geq \widetilde{c}
\end{array}\right.
\end{aligned}
$$

Case (a): $\left(\alpha w_{t}^{u} / p_{t}\right)<\left(\alpha w_{t}^{s} / p_{t}\right)<\widetilde{c}$. As follows from (2) and (11), an equilibrium in the agricultural good market will hold if $N_{t} \widetilde{c}=l_{t}^{u} N_{t}^{A} A_{t}^{a}$. Hence, $L_{t}^{a, N} / N_{t}=l_{t}^{u} N_{t}^{A} / N_{t}=\widetilde{c} / A_{t}^{a} \equiv L^{a}\left(\lambda_{t}\right)$. Similarly, using the equilibrium conditions in the manufacturing sector, $L_{t}^{m, N} / N_{t}=l_{t}^{u} N_{t}^{M} / N_{t} \equiv L^{m}\left(\lambda_{t}\right)$. Finally, as following from Lemma $1, H_{t}^{m} / N_{t}=l_{t}^{s} H_{t} / N_{t}=\left(h^{m}\right)^{*} l_{t}^{u} N_{t}^{M} / N_{t} \equiv H^{m}\left(\lambda_{t}\right)$, since $l_{t}^{u} N_{t}^{M} / N_{t}=L^{m}\left(\lambda_{t}\right)$. Hence,

$$
h_{t} \equiv \frac{H_{t}^{m}}{L_{t}^{a, N}+L_{t}^{m, N}+H_{t}^{m}}=\frac{l_{t}^{s} H_{t} / N_{t}}{\left(l_{t}^{u} N_{t}^{A} / N_{t}\right)+\left(l_{t}^{u} N_{t}^{M} / N_{t}\right)+\left(l_{t}^{s} H_{t} / N_{t}\right)} \equiv h\left(\lambda_{t}\right) .
$$

where $h^{\prime}\left(\lambda_{t+1}\right)>0$ since an increase in the level of technology, raises the wage level and leads to an increase in the budget share of manufactured good and hence a rise in the production of the manufactured good and thus an increase in the skill intensity of the labor force.

Case (b) $\widetilde{c}<\left(\alpha w_{t}^{u} / p_{t}\right)<\left(\alpha w_{t}^{s} / p_{t}\right)$. Equilibrium in the goods sector implies that

$$
\frac{Y^{M}}{p_{t} Y^{A}}=\frac{A^{M} f\left(\left(h^{m}\right)^{*}\right) l^{u} N^{M}}{p_{t} A^{A} l^{u} N^{A}}=\frac{f\left(h^{m}\right)^{*} N^{M}}{w^{u}\left(\left(h^{m}\right)^{*}\right) N^{A}}=\frac{\beta}{\alpha} .
$$

Since $l_{t}^{u}=l_{t}^{s}$, it follows that

$$
h \equiv \frac{H_{t}^{m}}{L_{t}^{a, N}+L_{t}^{m, N}+H_{t}^{m}}=\frac{l_{t}^{s} H_{t}}{l_{t}^{u} N_{t}^{A}+l_{t}^{u} N_{t}^{M}+l_{t}^{s} H_{t}}=\frac{H_{t}}{N_{t}} .
$$

Thus, noting that $H_{t}=\left(h^{m}\right)^{*} N_{t}^{M}$ and $N_{t}^{A}=\left[(\alpha / \beta) f\left(h^{m}\right)^{*} N_{t}^{M}\right] / w^{u}\left(\left(h^{m}\right)^{*}\right)$, it follows that

$$
h_{t}=\left(h^{m}\right)^{*} /\left[\left((\alpha / \beta) f\left(h^{m}\right)^{*} /\left(w^{u}\left(\left(h^{m}\right)^{*}\right)\right)+\left(h^{m}\right)^{*}+1\right]=\widetilde{h}\right. \text {. }
$$

Case (c): $\left(\alpha w_{t}^{u} / p_{t}\right)<\widetilde{c}<\left(\alpha w_{t}^{s} / p_{t}\right)$. Following the lines of arguments in case (a) and (b) the result follows.

\section{Appendix C}

This appendix demonstrates that the qualitative results would not alter if the production technology in the agricultural section remains land-intensive.

If the economy is characterized by 3 production technologies: an old agricultural technology, described in (1) and an old and new industrial technologies described in (3-4), one would need to replace Assumption A1-A3 with a stronger set of assumptions so as to assure that the technologically advanced economy would have a comparative advantage in the production of industrial goods.

In the three-technology model, the relative price of the agricultural good in terms of the manufactured good in period $t$, is

$$
p_{t}=\left\{\begin{array}{llc}
\frac{a_{t}^{m}}{A_{t}^{a}\left(L_{t}^{a, O}\right)^{\gamma-1}} & \text { if } & Y_{t}^{m, 0}>0 \\
\frac{A_{t}^{m} w^{u}\left(h_{t}^{m}\right)}{A_{t}^{a}\left(L_{t}^{a, O}\right)^{\gamma-1}} & \text { if } & Y_{t}^{m, N}>0 .
\end{array}\right.
$$


The productivity parameters are restricted such that in addition to (A1) and (A2)

The productivity of the new industrial technology advances more rapidly than that in the agricultural technology, i.e.,

$$
\frac{A^{m}(\lambda)}{A^{a}(\lambda)}=K^{\lambda} \text { for } K>1
$$

This implies that the technologically advanced economy will have a comparative advantage in the industrial sector if $K$ is sufficiently large.

The advancement in the productivity of the agricultural sector, $A_{t}^{a}$, with $\lambda_{t}$ is such that, at some point $\widetilde{t}$ where $h_{t}=\widetilde{h}$ the rate of technological progress rises sufficiently high so that the subsistence constraint will not bind in the future, i.e.,

$$
\frac{A_{t+1}^{a}\left(\lambda_{t+1}\right)}{A_{t}^{a}\left(\lambda_{t}\right)}>\left[(1-\alpha-\beta) / \tau^{u}\right]^{(1-\gamma)}
$$

where $h_{t} \geq \widetilde{h}$. In order to assure that the pattern of trade is consistent with historical patterns will assume that $K$ is sufficiently large for $p_{t}^{A}>p_{t}^{B}$, when the two economies begin to trade.

Lemma A2 Economy $A$ has a comparative advantage in the industrial good if $K$ is sufficiently large.

Proof. Noting (9), $p_{t}^{A}>p_{t}^{B}$ implies that

$$
\left[\frac{A_{t}^{m}}{A_{t}^{a}}\right]^{A} /\left[\frac{A_{t}^{m}}{A_{t}^{a}}\right]^{B}=K^{\left(\lambda_{t}^{A}-\lambda_{t}^{B}\right)}>\left(\frac{\left[L_{t}^{a, O}\right]^{B}}{\left[L_{t}^{a, O}\right]^{A}}\right)^{1-\gamma}
$$

Thus the inequality will hold for a sufficiently large value of $K$.

The rest of the results are established straightforwardly subject to (A1), (A2), (A3') and (A4'). 


\section{References}

[1] ACEMOGLU, D., JOHnSOn, S. and ROBInSOn, J.A. (2005), "Institutions as the Fundamental Cause of Long-Run Growth", in Aghion, P. and Durlauf, S. (eds.) Handbook of Economic Growth (Amsterdam: North-Holland).

[2] ACEMOGLU, D. and VENTURA, J. (2002), "The World Income Distribution", Quarterly Journal of Economics, 117, 659-694.

[3] ACEMoglU, D., and ZILIBOTTI, F. (2001), "Productivity Differences" Quarterly Journal of Economics, 116, 563-606.

[4] ASHRAF, Q. and GALOR., O. (2007), "Cultural Assimilation, Cultural Diffusion and the Origin of the Wealth of Nations" (CEPR Discussion Papers 6444).

[5] ATKESON, A. and KEHOE, P. (2000), Paths of Development for Early and Late Bloomers in a Dynamic Heckscher-Ohlin Model", (Bank of Minneapolis Staff Report \#256).

[6] BALDWin, R. E., MARTin, P. and OtTAVIAnO, G. I. P. (2001), "Global Income Divergence, Trade and Industrialization: The Geography of Growth Take-Offs", Journal of Economic Growth, 6, 5-37.

[7] BAIROCH, P. (1974), "Geographical Structure and Trade Balance of European Foreign Trade From 1800-1970", Journal of European Economic History 3, 557-608 .

[8] BAIROCH, P. (1982), "International Industrialization Levels from 1750-1980", Journal of European Economic History, 11, 269-333

[9] BARRO, R. J and LEE, J. (2000), "International Data on Educational Attainment: Updates and Implications" (Center for International Development, Harvard University).

[10] BASU, A. (1974), The Growth of Education and Political Development in India 1898-1920. (Oxford: Oxford University Press).

[11] BASU, S. and WEIL, D. N. (1998), "Appropriate Technology and Growth", Quarterly Journal of Economics, 113, 1025-1054.

[12] BECKER, G. S. (1981), A Treatise on the Family (Cambridge MA: Harvard University Press).

[13] CASELLI, F. and COLEMAN, J. W. (2001), "The US structural transformation and regional convergence: A reinterpretation", Journal of Political Economy, 109, 584-616.

[14] CHADHURI, K.N. (1983), Foreign Trade and Balance of Payments (1757-1947) in The Cambridge Economic History of India D. Kumar (ed.) (Cambridge: Cambridge University Press).

[15] CLARK, G. (1987), "Why Isn't the Whole World Developed?: Lessons from the Cotton Mills", Journal of Economic History, 47(1), 141-174.

[16] CLARK, G. and FEENSTRA, R. (2001), "Technology in the Great Divergence" (NBER Working Paper, $8596)$.

[17] CLEMENS, M.A. and WILliAmSON., J.G., (2004) "Why Did The Tariff-Growth Correlation Reverse After 1950?", Journal of Economic Growth, 9, 5-46.

[18] CRAFTS, N.F.R. (1985), British Economic Growth during the Industrial Revolution (Oxford: Oxford University Press).

[19] CRAFTS, N.F.R. and THOMAS, M. (1986) "Comparative Advantage in U.K. Manufacturing Trade, 1910-1935", The Economic Journal, 96, 629-645.

[20] DE LA CROIX, D. and DOEPKE, M. (2003), "Inequality and Growth: Why Differential Fertility Matters", American Economic Review, 93, 1091-1113.

[21] DOEPKE, M. (2004), "Accounting for Fertility Decline During the Transition to Growth", Journal of Economic Growth, 9, 347-383.

[22] ESTAVADEORDAL, A. and TAYLOR, A. M. (2002), "A Century of Missing Trade", American Economic Review, 92, 383-393. 
[23] ESTAVADEORDAL, A., FRANTZ, B. and TAYLOR, A. M. (2002), "The Rise and Fall of World Trade, 1870-1939", Quarterly Journal of Economics, 118, 359-407.

[24] FINDLAY, R. and KEIRZKOWSKY, H. (1983), "International Trade and Human Capital: A Simple General Equilibrium Model," Journal of Political Economy, 91, 957-978.

[25] FINDLAY, R. (1996), "Modeling Global Interdependence: Centers, Peripheries, and Frontiers", American Economic Review, 86, 47-51.

[26] FINDLAY, R. and O'ROURKE, K. H. (2001), "Commodity Market Integration, 1500-2000" in M. D. Bordo, A. M. Taylor and J. G. Williamson (eds.) Globalization in Historical Perspective (Chicago: The University of Chicago Press).

[27] FRANKEL, J.A., ROMER, D. (1999), "Does Trade Cause Growth", American Economic Review, 89, 379-399.

[28] FRANKEL, J.A., ROSE, A. (2002), "An estimate of the Effect of Common Currencies on Trade and Income", Quarterly Journal of Economics, 117, 437-466.

[29] GALOR, O. (2005), "Unified Growth Theory: From Stagnation to Growth," in Aghion, P. and Durlauf, S. (eds.) Handbook of Economic Growth (Amsterdam: North-Holland), 171-293.

[30] GALOR, O. and MOAV, O. (2002), "Natural Selection and the Origin of Economic Growth", Quarterly Journal of Economics, 117, 1133-1192.

[31] GALOR, O., MOAV, O. and VOLLRATH, D. (2006), "Inequality in Land Ownership, the Emergence of Human Capital Promoting Institutions and the Great Divergence" (Brown University).

[32] GALOR, O. and MOUNTFORD, A. (2006), "Trade and the Great Divergence: The Family Connection", American Economic Review, 96, 229-303.

[33] GALOR, O. and WEIL, D. N. (1999), "From Malthusian Stagnation to Modern Growth", American Economic Review, 89, 150-154.

[34] GALOR, O. and WEIL, D. N. (2000), "Population, Technology and Growth: From the Malthusian Regime to the Demographic Transition", American Economic Review, 90, 806-828.

[35] GLAESER, E.L., LA PORTA, R. LOPEZ-DE-SILANES, F. and SHLEIFER, A. (2004), "Do Institutions Cause Growth?", Journal of Economic Growth, 9, 271-303.

[36] GREENE, W. H. (1997), Econometric Analysis (New York: Prentice Hall)

[37] GROSSMAN, G. M. and HELPMAN, E. (1991), Innovation and Growth (MIT Press, Cambridge MA).

[38] HAINES, M. R. (2000). "The Population of the United States, 1790-1920", in Engermann, S. L. and R.E. Gallman (eds), The Cambridge Economic History of the United States, Vol. II, The Long Nineteenth Century, 143-205 (Cambridge: Cambridge University Press).

[39] HARLEY, C. K. (1999), "Reassessing the Industrial Revolution: a Macro View" in J. Mokyr, (ed.), The British Industrial Revolution: an Economic Perspective (Boulder: Westview Press).

[40] HALL, R. E. and JONES, C. I. (1999), "Why Do Some Countries Produce So Much More Output Per Worker Than Others?" Quarterly Journal of Economics, 114, 83-116.

[41] HOWITT, P. and MAYER-FOULKES, D. (2005), "R\&D, Implementation and Stagnation: A Schumpeterian Theory of Convergence Clubs", Journal of Money Credit and Banking, 37, 147-77.

[42] JONES, E. L. (1981), The European Miracle: Environments, Economies and Geopolitics in the History of Europe and Asia (Cambridge: Cambridge University Press).

[43] KRUGMAN, P. and VENABLES, A. (1995), "Globalization and the Inequality of Nations", Quarterly Journal of Economics, 90, 857-880.

[44] KUZNETS, S. (1967), "Quantitative Aspects of the Economic Growth of Nations : X. Level and Structure of Foreign Trade: Long-Term Trends", Economic Development and Cultural Change, 15 1-140. 
[45] LAGERLOF, N.P. (2006), "The Galor-Weil Model Revisited: A Quantitative Exercise", Review of Economic Dynamics, 9, 116-142.

[46] LANDES, D. S. (1998), The Wealth and Poverty of Nations (New York: Norton).

[47] LUCAS, R.. (2002), The Industrial Revolution: Past and Future (Cambridge: Harvard University Press).

[48] MADDISON, A. (2001), The World Economy (Paris : OECD).

[49] MATSUYAMA, K. (1992), "Agricultural Productivity, Comparative Advantage, and Economic Growth", Journal of Economic Theory, 58, 317-334.

[50] MATtheWS, R. C.O., FEINSTEIN, C. H. and ODLING-SMEE, J. C., (1982), British Economic Growth 1856-1973 (Stanford: Stanford University Press).

[51] MCCLOSKEY, D. N., (1981) "The Industrial Revolution, A Survey" in R.C. Floud and D.N. McCloskey, (eds), The Economic History of Britain Since 1700. Vol. 1 (Cambridge: Cambridge University Press).

[52] MCDERMOTT, J. (2002), "Development Dynamics: Economic Integration and the Demographic Transition", Journal of Economic Growth, 7, 371-410.

[53] MCEVEDY, C. and JONES, R. (1978), Atlas of World Population History (New York: Penguin).

[54] MOKYR, J. (2002), The Gifts of Athena: Historical Origins of the Knowledge Economy (Princeton: Princeton University Press).

[55] MOKYR, J. (1999), "The New Economic History and the Industrial Revolution," in J. Mokyr, (ed.), The British Industrial Revolution: an Economic Perspective, 1-127 (Boulder: Westview Press).

[56] MOKYR, J. (1985), The Economics of the Industrial Revolution (New Jersey: Rowman and Littlefield).

[57] NORTH, D.C. (1981), Structure and Change in Economic History (New York: Norton).

[58] O'ROURKE, K. H., TAYLOR, A. M. and WILLIAMSON, J. G. (1996), "Factor Price Convergence in the Late Nineteenth Century" International Economic Review, 37, 499-530.

[59] O'ROURKE, K. H. and WILliamSON, J. G. (1999), Globalization and History (Cambridge: MIT Press).

[60] O'ROURKE, K. H. and WILLIAMSON, J. G. (2005), "From Malthus to Ohlin: Trade, Industrialization and Distribution Since 1500," Journal of Economic Growth, 10, 5-34.

[61] POMERANZ, K. (2000), The Great Divergence: China, Europe and the Making of the Modern World Economy (Princeton: Princeton University Press).

[62] RODRIK, D., SUBRAMINIAN, A. and TREBBI, F. (2004), "Institutions Rule: The Primacy of Institutions Over Geography and Integration in Economic Development", Journal of Economic Growth, 9, 131-165.

[63] STOKEY, N. L. (1991), "The Volume and Composition of Trade Between Rich and Poor Countries," Review of Economic Studies, 58, 63-80.

[64] TREFLER, D. and CHUN ZHU, S. (2005), "The Structure of Factor Content Predictions" (NBER Working Paper No. W11221).

[65] WOOLDRIDGE J.M. (2002), Econometric Analysis of Cross Section and Panel Data (Cambridge, MA: MIT Press).

[66] WRIGLey, E. A. (1969), Population and History (New York: McGraw-Hill).

[67] YATES, P. L. (1959), Forty Years of Foreign Trade: A Statistical Handbook With Special Reference to Primary Products and Underdeveloped Countries (London: Allen \& Unwin).

[68] YOUNG, A. (1991), "Learning by Doing and the Dynamic Effects of International Trade", Quarterly Journal of Economics, 106, 369-405.

[69] ZEIRA, J. (1998), "Workers, Machines, and Economic Growth", Quarterly Journal of Economics, 113, 1091-1118. 